\title{
WOVEN THREADS: A CASE STUDY OF CHEMOTHERAPY NURSING PRACTICE IN A RURAL NEW ZEALAND SETTING
}

\author{
by
}

Glynnis Geraldine James

A thesis submitted to the Victoria University of Wellington in partial fulfilment of the requirements for the degree of Master of Nursing (Clinical)

Victoria University of Wellington

2008 


\begin{abstract}
This descriptive case study was undertaken to provide an account of chemotherapy practice in a nurse-led clinic located within a rural New Zealand area. The researcher, an oncology nurse specialist, worked along side colleagues for thirteen months to enable practice development. This clinic developed out of a need to have services closer to rural patients in order to address issues of equity, access, care integration and the fiscal and social constraints associated with the "cancer burden of care." The research provides a vehicle for the voice of the nurses to be heard who provide treatment to these patients. It is also an opportunity for me as the researcher to use the case study to articulate my own narrative and experiences of working and living in this area. Capturing the range of data applicable to this case; the ability to conceptualise it as a service within its context was possible using case study research methods. Four nurses involved in the chemotherapy clinic were participants in this study.
\end{abstract}

The findings of this study reveal that what could be perceived as barriers to outcomes and practice can in essence be turned into opportunities to develop new ways of caring for the patient and supporting nursing practice. These nurses view their practice as safe within the clinic despite resource constraints. They work in many ways to support each other and to cushion the patient from the impact of situational and contextual influences. Nursing practice was shown to evolve as a direct result of internal and external influences which were the impetus for nurses taking responsibility for their own competency.

This study also explored what it meant to be an experienced nurse but novice in a speciality practice. It challenges previously held assumptions that, to deliver chemotherapy successfully, a nurse needs to be operating from a previously held body of oncology nursing knowledge. Many challenges are faced on a day to day basis in a rural practice environment to just maintain consistent care and promote good patient outcomes. The nurses are well aware of their role in contributing to patient's quality of life and the roles they take to meet the growing needs of the patient as a consumer. This 
study delves into the multifarious nature of this nurse-led clinic and discusses the processes and relationships that are forged to deliver care.

Key words: case study; chemotherapy; nurse-led clinic; rural 


\section{DEDICATION}

This thesis is dedicated to my mother and the memory of my grandparents, special wonderful people who have showered me with love, believed in me and taught me that the only obstacles to success were those in my mind. Their influences in my life, commitment and dedication to my wellbeing have made and contributed to person I am today. I stand tall and strong because of these people. 


\section{ACKNOWLEDGEMENTS}

I would like to thank the following people for their unfailing help and support in my journey towards completing this thesis.

To my academic supervisor Margaret Martin, You have been my absolute rock. I thank you for your unfailing support, encouragement and belief in my abilities. There were many times when I needed a lifeline and you were there to pick up the pieces particularly when the going got hard.

To the administrative and academic staff at the GSNM\&H, Victoria University of Wellington, your support, help and role modelling throughout these years have led me to strive for a higher purpose. You have been a great source of inspiration to a girl whose formative years were grounded in the belief that I would not amount to anything because I was female and a person of colour. I thank you.

I would also like to acknowledge the funding I have received from various organisations throughout the years towards completing this academic qualification.

I would especially like to acknowledge my special family in particular my husband Gilbert, children Ashlynn and Phillip, without whose support this piece of work would not be realised. I thank you for all the back rubs and taking on of those tasks which allowed me to carry on writing.

I would like to thank my wonderful colleagues for their care and support during my time in their place and space. Thank you for your patience as I grappled with the challenges of living and experiencing rural life. This study would not have been possible without your valuable support and input.

And to all my nursing friends my life experiences have been enriched by meeting people who are not afraid to stand up, and be counted as part of this wonderful profession. 
Finally I would like to acknowledge, praise and give thanks to my God for giving me the strength to rise up like an eagle to achieve better things. 


\section{GLOSSARY OF TERMS}

Case Study:

Chemotherapy:

Nurse-led models of care:

Rural nursing:

Clinical Nurse Specialist:

Mentor:
A research strategy that investigates a phenomenon within its real life context using multiple sources of evidence to allow the exploration of interventions or things of special interest (Yin, 2003).

A single drug or combination of complex drugs used in the treatment of cancer

A model of care primarily based in the ambulatory care setting managed by nurses utilising advanced knowledge and skills (Loftus \& Weston, 2001).

Nursing in areas which are defined in terms of their geographical location, isolation, physical and human remoteness, population density and distance and access to healthcare services (MacLoed, Browne \& Leipert, 1998).

A nurse who is recognised as an expert in a defined area of knowledge and selected clinical practice (Raja-Jones, 2002).

An experienced nurse who role models standards of practice and who guides, advises and supervises the training of a less experienced nurse to assist in their practice development (Kilcullen, 2007). 


\section{TABLE OF CONTENTS}

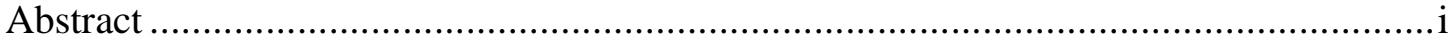

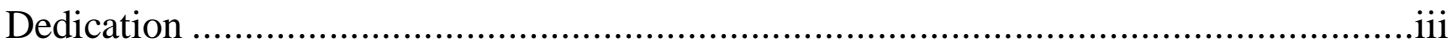

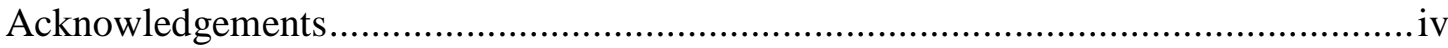

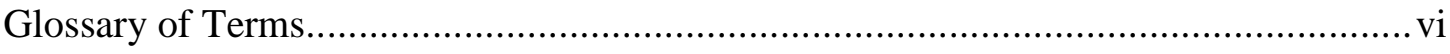

CHAPTER ONE: Introduction to Research - laying down the threads ......................... 4

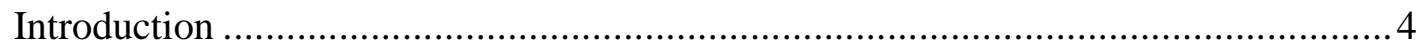

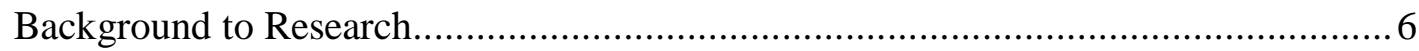

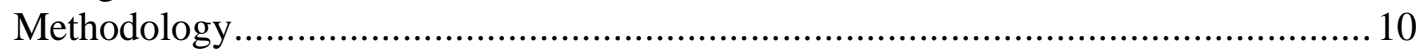

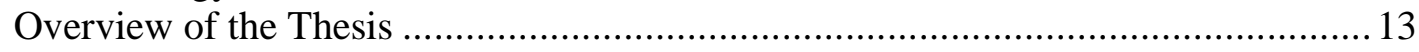

CHAPTER TWO: Local Context -the threads in the Fabric........................................ 16

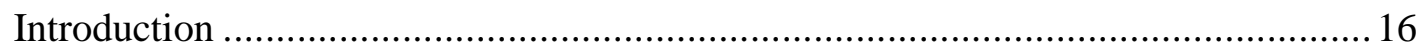

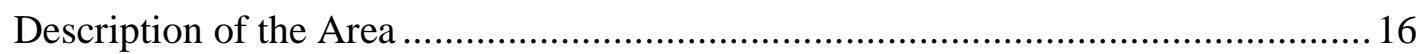

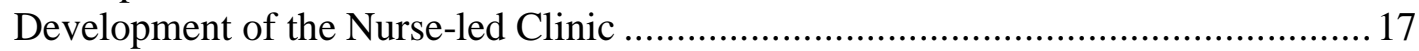

Changes within the New Zealand Healthcare System ............................................2 22

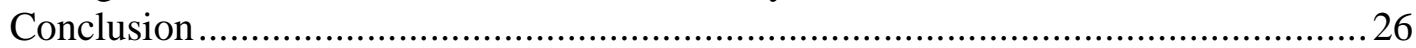

Chapter Three: A literature review - weaving the strands......................................2 27

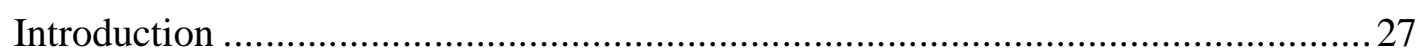

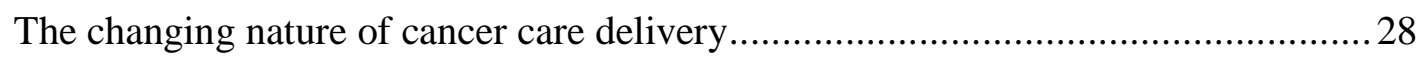

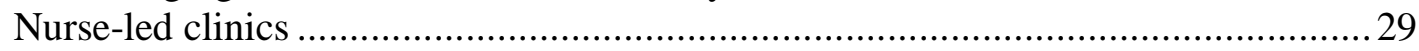

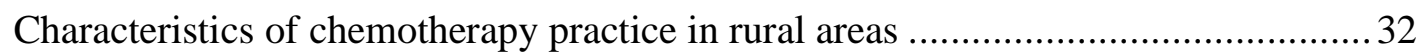

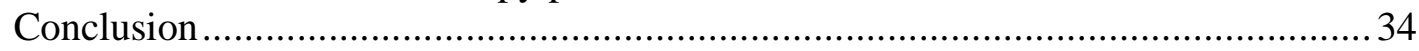

Chapter four: Design and Methods of Inquiry - the Strength of the Fabric ................... 36

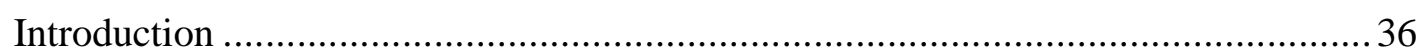

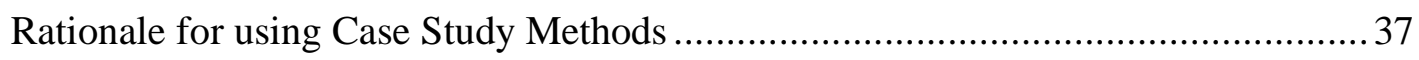

Case Study: A Methodology within the Qualitative Paradigm ................................ 37

Applicability of Case Study to Nursing Research ....................................................4 40

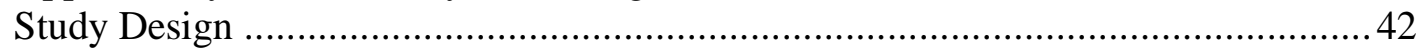

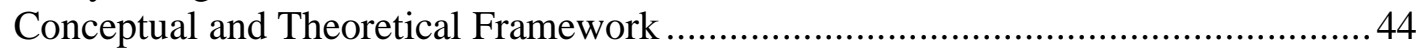

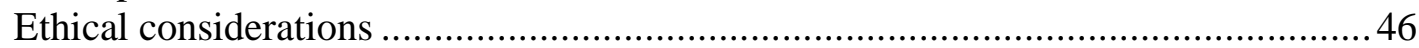

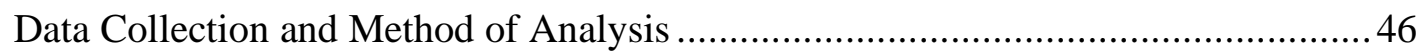

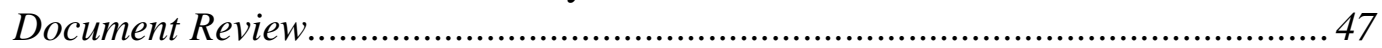

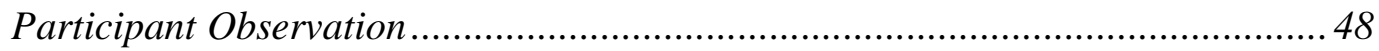

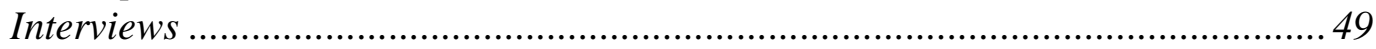

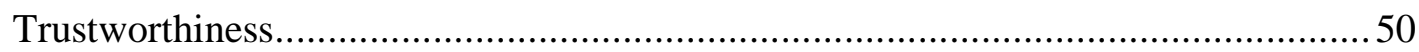

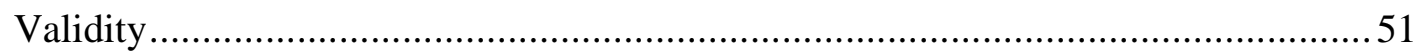

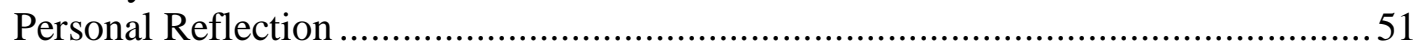

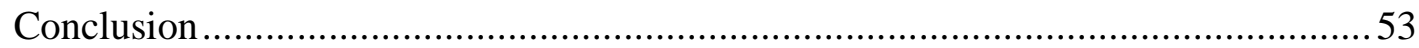

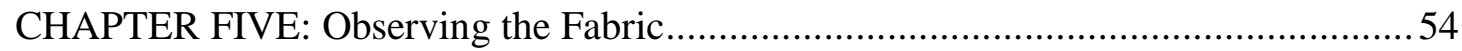

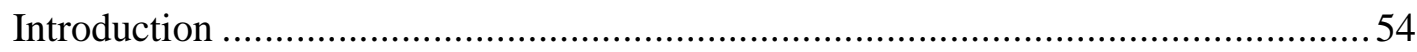

The Nature of Observed Practice....................................................................... 55 
Personal Reflections - Snippets from practice journal ….................................5 59

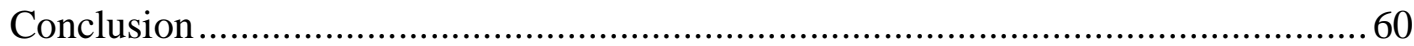

CHAPTER SIX: Study Findings - The Fabric that is the Clinic ..................................62

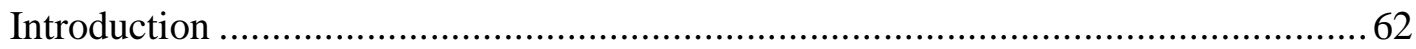

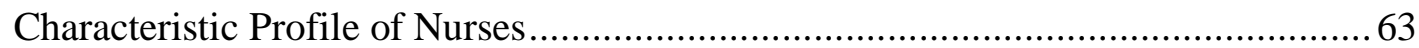

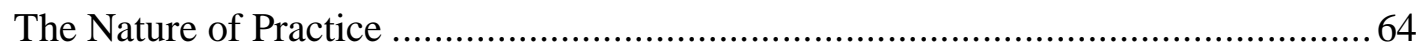

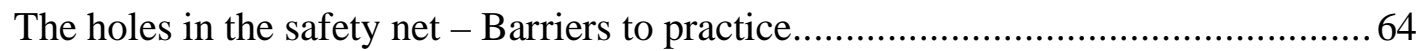

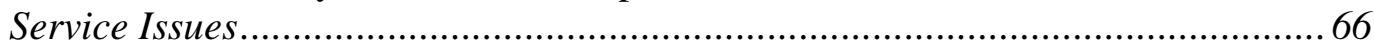

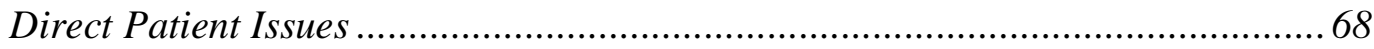

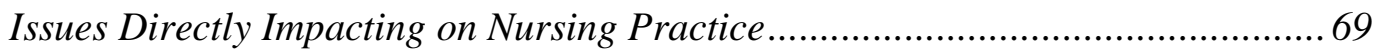

Cushioning the Impact - the Safety Net ............................................................. 73

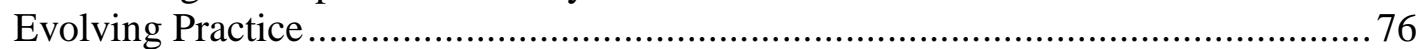

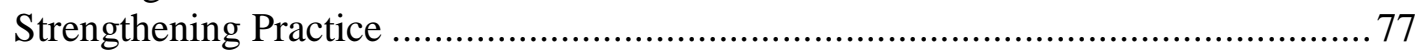

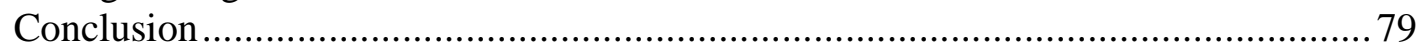

CHAPTER SEVEN: Discussion of Results - Maintaining the Fabric .......................... 80

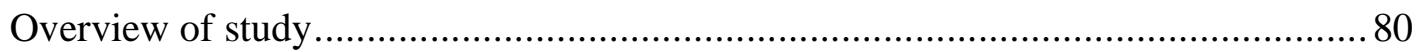

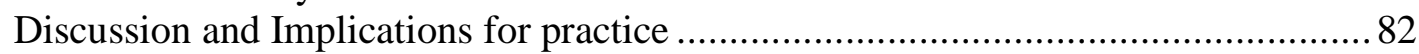

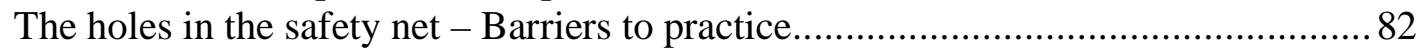

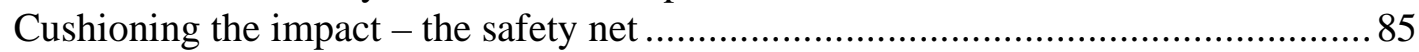

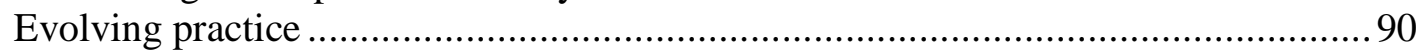

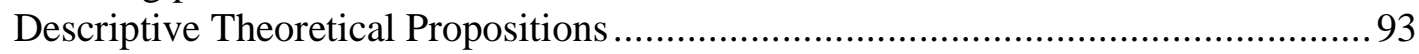

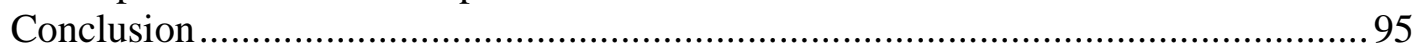

CHAPTER EIGHT: Conclusion - Laying the Fabric to Rest ....................................97

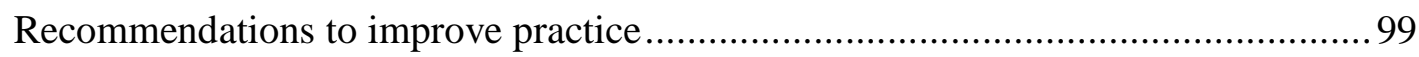

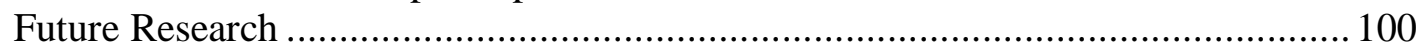

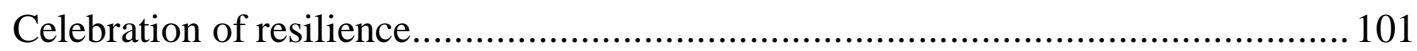

APPENDIX A: List of issue statements \& questions ................................................. 103

Appendix B: Prospective Participants Information Form........................................... 104

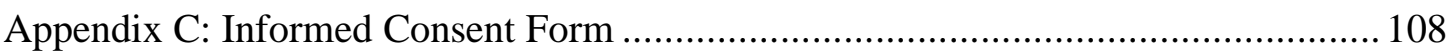

Appendix D. Confidentiality statement …............................................................... 109

Appendix E. List of Interview Questions........................................................... 110

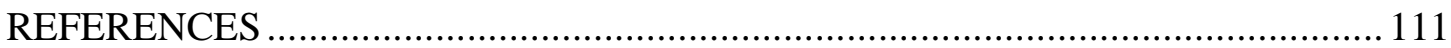




\section{LIST OF TABLES}

Table 1:Mitigating Reasons for Developing Oncology Nurse Position and Nurse-led Clinic

Table 2: Major themes: Chemotherapy Practice in a Rural New Zealand Setting...........62

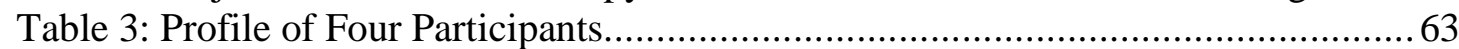

Table 4: The holes in the net: barriers impacting on practice ....................................65

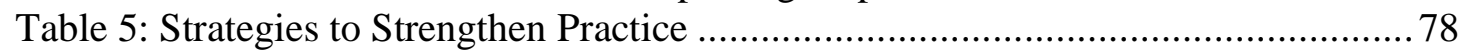

\section{LIST OF FIGURES}

Figure 1: Conceptual and theoretical framework: the case, context and multiple data points 


\section{CHAPTER ONE: INTRODUCTION TO RESEARCH - LAYING DOWN THE THREADS}

“To weave - to make fabric by interlacing yarn" (Collins et al., 2006, p. 838).

\section{Introduction}

As a clinical nurse specialist in oncology and palliative care I was seconded to a rural area of New Zealand for a thirteen month tenure to guide colleagues in developing advanced skills and insight into the delivery of chemotherapeutic agents. I felt confident to be able to share this knowledge having worked in an acute oncology and palliative care setting for the past six years. However, I also discovered rural life and the joys and challenges of nursing in a rural setting in New Zealand. This case study reveals as much about my journey during this year as it does about the colleagues with whom I had the privilege of sharing my expertise and time. The opportunity signalled acknowledgement in New Zealand that nurses do lead clinics for many specialised areas of the health services and (most) especially in rural and remote settings.

The current healthcare environment is characterised by rapid changes in both treatment and technology requiring nurses to be skilled at a clinical level with appropriate theoretical knowledge to effectively manage what is now proven to be complex patient care situations (Yates, 2001). This has certainly been my experience whilst working in this speciality area of practice as I've encountered newer cancer drugs, complex treatment regimens and new and improved devices aimed at improving administration techniques. I consider ongoing skills acquisition and professional development to be a taken for granted aspect of contemporary nursing practice. It is a Nursing Council of New Zealand (2003) professional requirement for all nurses to maintain competence and develop expertise. Cancer nurses in New Zealand and overseas subscribe to certain standards of practice and guidelines to define and ensure their quality of practice. Institutional credentialing for the delivery of chemotherapy is the norm in New Zealand 
(Jacobs, 2000) and this has been recognised by the Cancer Nurses Section of the New Zealand Nurses Organisation (NZNO, 2004). Historically this has been conducted by more experienced staff mentoring colleagues on the job. Nurses involved in administering chemotherapy in New Zealand are required to complete some form of formalised chemotherapy education, offered by the institutions they work in, on the job training and attain clinical proficiency in this type of treatment (NZNO). Many rural nurses attain their chemotherapy credentialing under the direction and supervision of experienced nurses in oncology services in larger centres. This is because many of the oncology services offered in rural areas have satellite links to major specialist centres whose oncologists are contracted to provide services to these areas. Thus the protocols, policies and procedures instituted for chemotherapy administration are usually adopted from guidelines in these centres and in some instances may be altered to reflect the rural situation.

My orientation and experience in rural nursing practice, coupled with the challenges of providing chemotherapy care in a nurse-led clinic, was the impetus behind this research. I used my secondment as an opportunity to look more closely into how this rural service managed to establish and deliver a highly specialised nursing service which requires advanced nursing practice. I was able to document this through describing the issues the nurses identified as affecting their practice. The result is a descriptive case study believed to be the first of its kind in New Zealand; it therefore has the potential to inform future research projects that will hopefully refine nursing practices for those delivering chemotherapy in rural settings.

This project provided me and colleagues with insight into the issues impacting on care. This enabled us to consider strategies during the project and these are aimed at generating improvements in the overall outcomes for both patients and healthcare professionals. This descriptive case study frames the delivery of chemotherapy as a speciality area of nursing practice located in a rural (based) hospital; it is based on my experiences and observations of the clinic setting and is informed by the conversations and interviews I conducted with the nurses. The case itself is made most explicit through 
the nurse's statements and my engagement with them. To elucidate the findings of this study I locate these insights within literature to build this picture of practice in its context.

I chose the concept of 'weaving threads of fabric,' to reveal the intricate process by which I analysed and then synthesized the data. This enabled me to provide a range of insights into the wealth of descriptive data I had gathered. I visualised rural practice and rural life as intertwined like threads in a piece of fabric. The many different threads are woven together to make a whole using the metaphorical fabric that reveals people in this setting to be durable and able to withstand adversity. The threads also signify the different relationships and connections that are essential to sustainable health care services. This case in fact identifies these threads and enables me to make this claim. The idea of threads, weaving and fabric have also provided a conceptual framework for the investigation and this sits alongside the notion of descriptive theory and enables the whole fabric to be considered a cohesive and recognisable case study to those who live and work in this setting. The hallmark of trustworthiness in research was of prime importance to me and so finding a way to present my findings of the case study using the fabric metaphor was satisfying for all. As will be described below I have chosen chapter headings throughout this thesis that convey this metaphor. For instance, Chapter One lays down the threads that form the basis for this research project, by providing the background to the research, its aims and objectives, the methodology used and the direction the thesis will take. This chapter also outlines my position as senior nurse and researcher within this body of work. Laying down these threads starts the weaving process towards gathering information, articulating ideas and understanding the gestalt of the research project, all of which form the foundation of what will ultimately be the fabric of this thesis.

\section{Background to Research}

My involvement with the nurse-led clinic delivering chemotherapy treatment in this rural setting came about as a result of my appointment as the oncology nurse specialist to this district for a period of thirteen months. My decision to work in this area was 
driven mainly by a desire to broaden my scope of practice and to experience new challenges that I was certain to encounter in my new role. I was aware that I would face challenges inherent in rural practice that were different from my experiences in the city. There were a number of issues I identified firsthand as impacting on my practice. These included the lack of onsite specialist oncology input and no peer review from oncology nurses. These increased my feelings of isolation and separation from what I had come to view as crucial support for my practice. I worried about my practice accountability and ongoing competency. I was working with limited healthcare resources, providing care for patients who lived long distances away. I felt I had an immense responsibility for the service combined with the fact that I was new to the area and unfamiliar with local culture. From my impressions and experiences I wanted to provide an account of nursing practice, particularly the delivery of chemotherapy, and provide insight into the issues the nurses saw as affecting their practice. The account was to be designed as a case study of chemotherapy administration and in line with case study methods the researcher's viewpoint and experiences as an insider in the case are just as crucial to the subjective experiences of the nurses working in the clinic (Yin, 2003). The location of this case study within its context regardful of subjective meanings and experiences allows a picture of the nature of practice to be reviewed.

Part of any large acute modern hospital setting is the provision of onsite oncology services which include the organisational and technical aspects necessary to maintain the day to day chemotherapy clinics. This involves diverse healthcare and administrative personnel and requires auxiliary services only seen in the larger city centres. Such services are designed to deliver complex care and are developed with relatively long term vision population growth plan as a baseline (Ministry of Health, 2005). A contractual agreement exists between the Specialist Oncology Centre located in another region and this DHB to provide oncology care for patients in this district. A medical and radiation oncologist visit monthly and the oncology nurse provide a key role in care integration and support. In New Zealand the systematic development of cancer care services has occurred in six main centres, Auckland, Hamilton, Palmerston North, Wellington, Christchurch and Dunedin. A full service would be considered a site where 
surgery, radiotherapy and chemotherapy services are available for people of that region both urban and rural. Education and training of staff is considered critical to the ability of such a centre to deliver services that are deemed leading edge. This means that such centres maintain a strong research and development focus with the aim to deliver the best treatment known internationally to the population (Ministry of Health, 2003a, 2005). While the services are funded by the Ministry of Health coordination and management of the services occurs for the region through these Cancer Centres. They are hubs from which regional services span out to connect the rural population in diverse way. Understanding the national picture of cancer services in New Zealand is important in view of the projected increase in cancer patient numbers but also for future service configurations.

In the rural area where I was seconded from one of the main cancer centres I found the oncology nurse combines the roles of a number of personnel that would be located in a city hospital. I was responsible for ensuring that the treatment was prescribed; the pharmacy had timely access to the scripts; the patients knew when treatment was to occur; that a room was available to give treatment; that patients had bloods taken on time; that enough time was allocated for the treatment; that the clinic had staff to administer treatment. The list is exhaustive but encapsulates the complex processes behind ensuring a successful treatment outcome. The case study will reveal how events such as inadequate staffing resources or the non arrival of chemotherapy drugs impacted on patient treatment schedules and interrupted the smooth operation of the clinic.

Chemotherapy practice is acknowledged as challenging and complex and this is due to the nature of the drugs involved and the complex process taken to facilitate smooth delivery of treatment (Gilbar, 2001; Lasselter \& Wernick, 2003; McCarthy et al., 2003). There is no research nationally identifying the specific issues in nurses delivering chemotherapy in rural and remote areas. In fact there is little research into this issue internationally and most of the research appears to come from Australia. My case study closely resembles that of McCarthy et al. who through the use of survey methods were able to document the nature of chemotherapy practices in Australia. Many contextual 
and situational influences were found to impact on the safe delivery of chemotherapy in rural areas and amongst these were human and financial resources, geographical location and distance from treatment centres (McCarthy et al., Tanghe et al., 1996; Yates et al., 2000). The nurse-led clinic in this rural area is not exempt from these influences and the nurses face many challenges to maintain their skills and practice. The identification of the issues through conversation with the staff and observation of the conduct of practice was intentional with the aim of providing a way of ensuring that old practices were reviewed, refined and new strategies generated with the ultimate aim of improving service outcomes for patients, nurses and healthcare professionals alike.

While my aim for the project was to describe the nature of chemotherapy, I wanted to provide an insider's account of practice in this clinic. Obviously this account is through my eyes as the specialist oncology and palliative care nurse engaged to work alongside staff to enable further professional development in chemotherapy practice. This case study is unique for several reasons amongst which are that it locates a highly specialised service managed by nurses in a rural area. This will become evident in the body of the thesis. Although it was not the focus or intention of the thesis I also argue that this work reveals my expert practice as a chemotherapy nurse. The dynamics of practice and the ways it informs itself and engages those involved revealed to me that to divorce myself from the situation would be an act that would diminish my integral role and contribution to this practice environment. By reason of choosing case study method as a strategy and being the nurse delivering education in this setting of course I would be describing my own practice. Initially this position did not sit comfortably with me. However, I came to understand that I needed to position myself within the body of this work and that my contribution and practice, although viewed as secondary to the research was a crucial factor underpinning the integrity of the study. 


\section{Methodology}

I chose to use a case study approach both as method and as the vehicle for describing the nurses' practice. This choice is congruent with the traditions of Lincoln and Guba (1985) and Yin (2003) and importantly allows me to locate my professional impressions and experiences as I was engaging both as a clinical educator and researcher with the nurses. This position and its ethical considerations are explained in chapter four in which I describe the research methods. The thesis touched on many areas of practice however it is important to identify what this thesis is not about. The thesis does not intend to explore the role of the Nurse Practitioner which is currently developing in New Zealand, (although this is pertinent because these nurses conduct research as integral to their practice). Nurses are most likely to deliver chemotherapeutics agents to patients with cancer and the contemporary New Zealand context where such practices are occurring are being identified as nurse-led clinics. There is little research into actual chemotherapy practices in nurse-led clinics internationally (Fitzsimmons et al., 2004) and none to my knowledge nationally. My intent in describing practice is to present the clinic as a unique case and this has wider implications for both the patients and nurses. It is not the intent of this study to investigate the organisation or the cancer services of the region or even comment on service delivery in which this practice is located; however it is important to understand the context in which practice occurs. Any comments made in the research to the service have been most carefully researched with respect to ethical requirements for confidentiality of staff, patients and location of the service.

Descriptions of the organisation and service are therefore made in the interests of locating the value and insights of comments made by the nurses in the clinic in relation to their practice goals and expertise.

The case study approach enabled me to gather descriptive data to reveal a detailed picture of practice and to also locate a highly specialised nursing service in its context. This method is an appropriate research strategy particularly when applied to new areas of research which delve into real life situations (Graziano \& Raulin, 1993; Pegram, 2000; Sandelowski, 1996). I began the study with many objectives and gradually refined 
the focus of what I was most interested in revealing when I began to appreciate the challenges for the nurses in the setting. This honed in on the issues the nurses identified as affecting practice and uncovered insightful glimpses into practice which will be the focus of discussion in Chapter Seven. The case will present recommendations for service improvements with the intention of contributing a rationale for arguments made through the case study for improved patient and nursing outcomes. Furthermore, the study seeks to test two theoretical propositions that I developed to assist me with the direction and focus of my investigation. In developing these propositions I was making hypothetical statements that firmly positioned the focus of the inquiry of the case. This positioning created structural scaffolding that ensured that I made links between the data and propositions to either support or refute them within the course of the investigation. The first theoretical proposition I developed sought to examine how the survival and support of chemotherapy practice in rural areas was grounded in mutually beneficial relationships fostered by contextual influences in and around practice. The second theoretical proposition sought to test my assumption that if attention was paid to developing a nurse's knowledge and skills, whilst providing her with access to appropriate resources; these would provide the patient with greater protection and improve chemotherapy outcomes. The underlying assumptions guiding these statements and links to the data collected will be examined and discussed in Chapter Seven in light of the findings of this study. According to Yin (2003) theoretical statements direct attention to something that should be examined within the study and provide direction when looking for relevant evidence. For example, this study will examine relationships that support the infrastructure of the service given the relative isolation from mainstream oncology services. It will also delve into issues of education, competency and skills acquisition in light of contextual influences.

The New Zealand healthcare environment is evolving in response to fiscal constraints and consumer demands. Nurse-led clinics are a prime example of the innovative ways nurses have responded to these challenges (Loftus \& Weston, 2001). It's fortuitous that this service has developed within a timeframe when the New Zealand government's healthcare policies are geared towards developing services in local areas pertinent to 
population needs. The initial description of the service and the immediate impressions of the context need to be located within the radical changes within New Zealand's healthcare environment that have taken place over the last two decades and this will be discussed in more detail in Chapter Two. The current government has made a commitment to strengthening primary health care services based on international evidence and the belief that this will lead to improved health outcomes and reduced costs (Hodgson, 2006). One strategic vision linked to improved care in the future is the emergence of new models of nursing practice that will play a greater role in managing chronic disease in the New Zealand population (Hodgson). As a sign of its commitment the current government had provided funding from the year 2004 to 2006 for eleven Innovative Models of Primary Health Care Nursing (http://www.moh.govt.nz/moh.nsf/indexmh/nursing.in). The criteria for funding maintained that these models be grounded in primary health care, strengthen nursing leadership in this area, and meet the objectives of the Primary Health Care Strategy (2001c). These projects have also been subject to the process of evaluation to assess their effectiveness and have had varying degrees of success (Primary Health Care Nurse Innovation Evaluation Team, 2007).

No service or system is perfect, and in order to improve the quality of care delivered, the issues that affect practice must continue to inform the debate that will lead to safe care. This study sought to sensitively highlight the issues affecting the practice of nurses delivering chemotherapy in this setting. Through exposing these issues and detailing the internationally approved processes for best practice I considered that we could collaborate in making a case for quality and audit improving practice. This research will add to nursing knowledge on rural chemotherapy practices and hopefully establish a point of reference for future research into this subject. It will also provide suggestions and strategies for current and future service developments that can be used to influence care in both rural and nurse-led services. 


\section{Overview of the Thesis}

This introductory chapter outlines the objectives of the research project providing a background to understanding why this line of inquiry was undertaken, the methodology used and the importance of this study to rural nursing chemotherapy practice issues. The way in which service based issues are addressed in complex cancer services was introduced in this section.

Chapter Two provides a rich description of the area and the background that led to the development of this nurse-led clinic. It also provides an overview of the wider socioeconomic and political influences on the international cancer healthcare setting and reforms in New Zealand. It provides insight into the wider influences impacting on nursing care, by building the case that informs the research question under study.

The focus of Chapter Three is a review of the literature in relation to the changing nature of cancer care delivery and the place of nurse-led clinics in this environment. I will also discuss the challenges of chemotherapy delivery in rural settings and highlight the characteristics of practice amidst contextual and situational influences. This will provide insight into the impact of the wider influences on the cancer practice setting.

In Chapter Four the research methodology is introduced and the rationale behind using a qualitative approach is explained. Descriptive case study methods are utilised to answer the research questions. I discuss the research design, ethical considerations, data collection methods and analysis techniques. I describe the process in which I reached a point where I could identify the dominant themes solicited after much review of the data. Included in this chapter will also be a discussion of the limitations of the study and the difficulties encountered during this phase of the study.

Chapter Five is devoted to a case narrative describing the nature of observed practice through the lens of the researcher. This is to firstly provide a vicarious experience for the reader allowing them a glimpse into what chemotherapy practice entails in this setting. Secondly this account also provides additional validation of the study and builds on the 
evidence gleaned from the nursing interviews which will be presented in Chapter Six. This chapter ends with a reflective account of some of the researcher's experiences to provide additional insights into this practice environment.

The aim of Chapter Six is to present further evidence to inform the study. This was gleaned from the data analysis of the interviews of research participants. The research focused on the issues that the nurses identified as affecting their practice. A profile of the nurses working in this setting is presented along with a description of practice as revealed through three predominant themes consistently identified from this data. The chapter concludes with the suggestions the nurses proposed that could be used to enhance practice. Overall, this chapter provides many essential answers to my question about issues in a nurse-led clinic from the perspective of participants involved in this practice setting.

In Chapter Seven there is a discussion of the study findings and the implications for practice revealing new insights into this research with reference to supporting literature to verify or challenge the results. Suggestions are made to improve practice and care in this setting. The intent is also to provide a forum for discussion which hopefully will be used to maintain, strengthen and enhance the fabric of this practice.

Chapter Eight concludes the case study and provides a summation of the research and key findings. It also concludes with suggestions for future research thereby linking all the threads of this fabric.

There are few studies addressing rural chemotherapy practice issues and these appear to come from Australia. Little is understood about the nature of chemotherapy practice in rural New Zealand settings. The aim of this descriptive case study was to document the delivery of a highly specialised nursing service in a rural nurse-led clinic. The findings from this study will be used to plan for further research and to support recommendations to improve the service that is provided to rural patients. The goal is also to improve the working conditions of the nurses in chemotherapy clinic settings. The findings of this 
case study do offer suggestions for how these nurses can maintain competence and develop expertise in their practice. 


\section{CHAPTER TWO: LOCAL CONTEXT -THE THREADS IN THE FABRIC}

“Threads -strands or filaments of yarn used in weaving” (Collins et al., 2006, p. 777).

\section{Introduction}

The purpose of this chapter is to position the study in its context. Towards this aim I provide a general description of the area in which the clinic is located and its people. I wanted to examine the context in which this service was developed incorporating the wider socio-economic and political influences that have precipitated changes within the healthcare sphere of New Zealand. The way nurses practice and the shape of current and future services is driven by intrinsic and extrinsic influences. This case would be less informed if the context of these influences were not considered. In accordance with case study methodology, documents I considered to be relevant to the context of the clinic and nurses practice were examined to provide background information about this case and enable me to develop some understanding of the practice context. The methods used to review these documents will be discussed in more detail in chapter four which sets out the research methods. The timely development of this service has occurred within a period where the New Zealand government's healthcare policies are geared towards supporting nurse-led initiatives pertinent to population needs (Ministry of Health, 2003b). The use of metaphor to create a picture of threads intertwined and woven through a piece of fabric is carried throughout the thesis to facilitate the understanding of the different parts that make this case. The use of metaphor sits alongside Yin's (2003) idea of descriptive theory which I use to reveal a picture of this practice in context. These threads form part of the strands that contribute to the fabric that is essentially the case study of this practice.

\section{Description of the Area}

New Zealand is described as a land of vast contrasts which are apparent in its shape, flora, fauna, dramatic scenery and climatic variations. The area of interest is recognised 
as a predominantly rural area of New Zealand which is well known for its stunning landscapes marked with lush green vegetation and abundant waterways in the form of rivers, lakes and scenic coastlines. This area has an above average rainfall in comparison with the rest of the country and a mild temperate climate (Wikipedia, 2007). This region encompasses an area of 23,000 square kilometres and the most recent census data indicates that there is a population of approximately 31, 000 people (Statistics New Zealand, 2006). Early European settlement was influenced by the discovery of gold and coal in this region. The economic activities that engage the people of this place are focused mainly around mining, forestry, farming, fishing and ecotourism (New Zealand Tourism, 2006). The nurse-led chemotherapy clinic is located at the base hospital in the largest town of the region. This hospital is the focal point for medical care in this area and offers a range of medical services supported by visiting specialists from other centres. In addition the health needs of the community are supported by general practitioner services and rural nursing centres situated at strategic places in the area (WCDT, 2005). Some patients have to travel significant distances to access care at the hospital because of their rural abode. For those patients requiring advanced diagnostic procedures and specialist care (not provided by the hospital) a trip to a major city hospital can take anywhere from three to six hours or more depending on their place of abode. Public transport is limited and in some areas non existent however there are good road, rail and air links with major urban centres. The people of this area have a reputation for being warm, friendly, hospitable and stoic. These attributes I found from my association with them contribute to their distinctive rural culture which carries with it a strong sense of community spirit and support for each other.

\section{Development of the Nurse-led Clinic}

The nurse-led clinic (NLC) in this rural base hospital was a relatively new service, just over two year's duration when I encountered it. The background to why it was established relates to the year 2000 when concerns were expressed by the visiting oncologists and local Cancer Society regarding the lack of support and care coordination for oncology patients in the area. (References for supporting documents are not provided in this section due to confidentiality and anonymity issues). Dialogue was entered into 
with the local District Health Board (DHB) to see how cancer services could be improved for patients in this area. These concerns were many (see Table 1).

\section{Table 1: Mitigating Reasons for Developing Oncology Nurse Position and Nurse-led Clinic}

Increasing demands on visiting oncologists regarding the ongoing care of patients Increasing patient demands on the local cancer society

Poor service coordination and minimal support for oncology patients

No appointed person to assist with patient care coordination

Lack of access and inconsistency of chemotherapy treatments locally

No specialized nursing input

Doctors administering chemotherapy had little or no experience in this practice area Nursing shortages impacting on staff availability for training

High general practitioner turnover in the area compromising care of oncology patients Inadequate cancer support education

\footnotetext{
Also of interest was the fact that the number of patients receiving treatment in this area had declined markedly and this was thought to be due to a lack of trained personnel to administer chemotherapy. There was no appointed person to coordinate care for oncology patients and this was identified as a risk factor in their outcomes. Many patients and support persons found the social and financial cost of travelling long distances to receive treatment prohibitive. For many patients treatment decisions were based on and influenced by the distance from the specialist services. The documents show that the establishment of an oncology nurse position in 2002 and the clinic in 2004 were in response to these concerns. They established a rationale for the reduction of patient distress and aimed for improved patient outcomes by establishing services closer to patients.
} 
The development of this service coincided with the DHB's attempt to address cancer care gaps within its service in line with strategic government documents. These were, The New Zealand Health Strategy (Ministry of Health, 2000), He Korowai Oranga The Maori Health Strategy (Ministry of Health, 2001a), The Palliative Care Strategy (Ministry of Health, 2001b), The Primary Health Care Strategy (Ministry of Health, 2001c), and The New Zealand Cancer Control Strategy (Ministry of Health, 2003a). In its assessment report into the health needs of its population the DHB recognised the socio-economic impact on patients having to travel long distances to specialist centres and stated its intent to improve access to local chemotherapy services for eligible patients (Wellington School of Medicine, 2001). At this stage little chemotherapy was being given in this area for the above mentioned reasons. Although this clinic serves the needs of some patients in the region, I need to point out that all paediatric and most haematology patients and a certain percentage of oncology patients still continue to receive their treatment at the distant specialist services. This is because of the client type and speciality input that this service is not geared to offer. It may also be a result of personal patient preference and the perceived perception that better treatment and care is given in the city. This DHB has a contractual agreement with this regional Specialist Oncology Service some 250 kilometres away who provide medical and radiation oncology care for cancer patients in this district. These oncologists hold monthly clinics and dependant on the services required, some patients have to travel to the main centre for further treatment and support. This clinic was established to provide certain chemotherapy treatments and ongoing support for chemotherapy patients. It is linked and supported by this off site Specialist Oncology Service who also provides accredited chemotherapy training for the nurses working in this clinic.

My appointment to work in this area was as the Oncology Nurse Specialist. A meeting with the three nurses involved in chemotherapy administration at this hospital revealed that they had arrived from various clinical settings around the hospital. On introducing ourselves to each other we all found that we had wide ranging experience in our backgrounds. It made sense when they related their diverse expertise and related how they simultaneously sustained multiple roles in other clinical areas of the hospital. 
As we shared in this introductory stage the nurses were able to share with a colleague who had insight into the demands of delivering chemotherapy. The nurses revealed that one of the challenges they encountered in practice was the constraints on their time and availability in the chemotherapy clinic. I reflected on this and considered that in my experience infrequently administering chemotherapy does not provide adequate opportunity to develop the nurses' theoretical and clinical knowledge in chemotherapy. Of course this occurred in this setting because there were limited patient numbers. When I reflect back on my nursing career I learnt my craft through direct involvement with patients, observing others, mimicking them, through mentored relationships and acquiring knowledge and skills through training and theoretical education. Nursing practice is firmly grounded in experience which takes place against a background of experiential learning, theoretical knowledge, cognitive skills and processes to execute the art and craft of practice (Benner, 1984; Evans \& Donnelly, 2006; Tabari-Khomeiran, Kiger, Parsa-Yekta \& Ahmadi, 2007). Nursing Council of New Zealand (2003) requirements for competency include a component which encompasses direct care giving and professional development hours to be certified competent or proficient. The International Council of Nurses recognises that a number of factors influence the domain of competency and they maintain that: "The competence of an individual nurse within the legal scope of practice is influenced by a variety of factors including education, experience, expertise and interests as well as the context of practice" (International Council of Nurses, 1998).

There is a plethora of literature about competency issues and definitions. However these are framed, one thing is consistent; competency is articulated through a range of descriptive actions and behaviours and encompasses many dimensions of practice specific to its context (Arbon, 2004; Evans \& Donnelly, 2006; Meretoja, Eriksson \& Leino-Kilpi, 2002; Tabari-Khomeiran et al., 2007). According to Benner (1984) any nurse entering a new speciality practice area and who is unfamiliar with the accompanying patient care practices is in essence reduced to a novice level of practice. When acquiring a new competency in a clinical area it is usual to frame acquisition and maintenance of competency in terms of numbers of clients seen with various protocols 
and conditions. The range and diversity of patients and the experiences derived from direct care giving actions then enables the nurse to extend their expertise.

The reports I had read to understand the region and service indicated that there were a number of eligible patients who could have their treatments in this area. Because no service was available this group of patients were accessing care at the specialist centre at great financial and social cost. The nurses in the clinic were able to corroborate these reports and indicated that the development of the clinic in which some of them had being involved, had relieved what they regarded as the cancer burden of care experienced by some patients. I was interested in this being stated at the outset and recognised their ability to advocate and assess the bigger picture and longer term trajectory of care that is required for cancer patients and their families. These nurses were long time rural residents and showed in-depth insight into the issues affecting patients and access to services. Most of these nurses have been involved with their patients often from the point of initial diagnosis and in their capacity as fully functioning members of this community.

The impact of cancer on New Zealand's society is a current contemporary issue and is reflected in the government's stand to reduce the impact of this illness by making it the subject of a strategic action plan. Deaths from cancer are on the increase and The Cancer Control Strategy (Ministry of Health, 2003a) rates it as the leading cause of death in New Zealand accounting for 29 percent of deaths from all causes. The objectives in the supporting Cancer Control Action Plan (Ministry of Health, 2005) are directed at reducing the prevalence and impact of cancer in our society by investing in activities that will provide better prevention, screening, timely access to treatment and support of cancer patients. The impact of this 'burden of cancer' as articulated in this document is as much a reality for these nurses involved in their patient's care as it is for the patients themselves. I was able to use this as a context to position and describe my previous involvement with chemotherapy practice and what I could bring to share with colleagues in this nurse-led clinic. I knew that my appointment as the oncology nurse specialist to this district would be for a period of thirteen months and during this time I revealed that 
I wanted to engage with them in a project documenting the nature of chemotherapy practice, particularly as it pertained to a rural nurse-led clinic. While they were somewhat nervous at the idea of their work being the subject of research they were enthusiastic about revealing the uniqueness of what they knew they contributed. I indicated that given the changes in the health care system in New Zealand that this would make a worthwhile contribution.

\section{Changes within the New Zealand Healthcare System}

In order to appreciate the nature of delivering any complex service that is considered highly specialised to people who are themselves life threatened, it is critical to understand the political and social context within which it is located. This clinic is important, not only because it is a nurse-led service but because it exists to alleviate the burden of cancer care experienced by patients in this region. The initial description of the service and the immediate impressions of the context need to be located within the radical changes within New Zealand's healthcare environment that have taken place over the last two decades. A brief overview is provided of some of these changes.

In 1993 the public health care system was radically restructured with health reforms geared towards a market orientated model based on overseas trends (Ashton, 1999). There were changes in the way hospitals provided services with reductions in the number of available hospital beds. Barnett (2000) explains that this trend is consistent with international experience and could be explained by the decline in the relevance of the hospital as a therapeutic environment. These changes have occurred amidst a climate of increasing costs and changes in clinical practice. Many changes have proved to be unpopular with the general public and healthcare professionals alike (Ashton). The healthcare policies and practices of this era had resulted in a reduction in public and professional confidence in the government's ability to look after the health of its people. Health remains, and has always been a contentious political issue and the Labour Government's 1999 pre-election promise sought to restructure the healthcare system to one that was responsive to public demands (Ashton). Change is not always perceived in 
a positive light and this in part depends on how that change impacts on a person at an individual level.

A survey by Barnett and Coyle (1998) provided evidence of the wider implications of the government's socio-economic restructuring. Lower socioeconomic groups were struggling to access health care. This became identified as the access and equity principle and later became enshrined in policy as a key performance indicator (New Zealand Public Health and Disability Act, 2000). Despite healthcare and technological advances New Zealand, in comparison with other developed countries has significant health disparities. These are found amongst different socio-economic and ethnic groups and those living in geographically isolated areas (Ministry of Health, 2002b). According to Gauld (2001) the government's new focus was towards a more patient focused approach, with greater centralization of core and specialist services. The shifts in health care services were argued as being towards addressing the socio-economic determinants of health and illness. The compelling aim of the government's health care strategies (Ministry of Health, 2000, 2001a, 2001c, 2003a) was to reduce healthcare inequalities and improve the overall health of the New Zealand population. Achieving this occurred in two areas; it meant getting to the roots of the nation's health problems, by addressing the issues that impacted on health and strengthening primary health care services by encouraging flexible, appropriate and affordable models of care. Strategic policies were developed to address individual diseases that caused the highest mortality such as cardiac, respiratory and cancer. The Cancer Control Strategy Action Plan was aimed at reducing the burden of disease in the population (Ministry of Health, 2005). This was in line with the World Health Organisation recommendations that maintain that countries who desire to reduce the impact and incidence of cancer are best served by implementing strategic plans at national level (Ministry of Health, 2003a). These strategic documents had stated goals and targets for delivering health care organisationally. Key to the delivery of the services would be well trained professionals. Clinical Training Agency funds were sourced centrally from the Ministry of Health to encourage staff across the healthcare spectrum to upgrade their expertise through targeted postgraduate education (Ministry of Health, 2002a). 
At an organisational level the health restructuring of the early 2000's saw the deestablishment of Health Funding Authorities in regional areas and the transition to District Health Boards. Their task was to build partnerships with their communities to provide appropriate health and treatment services (Gauld, 2001). The New Zealand Health Strategy (Ministry of Health, 2000) had provided a framework for DHB's to improve healthcare disparities. This goal meant that the government and the healthcare sector would have to work closely to identify and address problems and issues associated with poor health outcomes. Closing the gaps meant identifying and removing those barriers to care, equitable access to appropriate services, better care integration and coordination of services. A commitment had also been made to workforce development and research activities with ongoing monitoring and evaluation of services at a local level (Ministry of Health, 2000). The government has challenged DHB's to develop programmes in line with specific community needs. As part of this remit DHB's were provided with Cancer Control Toolkits whereby a number of prescriptive strategies were suggested for them to institute (Ministry of Health, 2003a). Amongst these included programmes directed towards smoking cessation, reducing sunscreen exposure, promoting safer sexual behaviours, healthy eating and increased breast and cervical screening. The current government made a commitment to strengthening primary health care services based on international evidence and the belief that this will lead to improved health outcomes and reduced costs (Hodgson, 2006). In 2005 Pete Hodgson, the Minister of Health, announced funding for fifteen projects that would advance the goals of the Cancer Control Strategic Action Plan 2005-2010 (Hodgson, 2005). Some of these projects were aimed at mapping the New Zealand cancer patients' journeys and clinical pathways. In 2006 with funding from the Ministry of Health and in partnership with the DHB, Cancer Society and a local Charitable Trust a research project was undertaken in this region to map the journeys of 19 cancer patients (Doolan-Noble, McKinley \& Cormack, 2006). The intent of this project was to identify service gaps and provide insight into the experiences of cancer patients and health professionals in this region. The knowledge from this study will be used to inform current and future service 
developments that will hopefully reduce the impact of cancer on the population in this region.

The shifts in our healthcare system towards a primary healthcare focus are apparent in the number of nurse-led initiatives that are emerging in response to these changes and as a direct result of government funding (Ministry of Health, n.d.). The government's expectation is that nurses will play a greater role in managing chronic disease in the New Zealand population (Hodgson, 2006). One example of the government's commitment to strengthening its primary healthcare focus and nursing leadership is the Counties Manukau Innovation Project.

The Counties Manukau Primary Health Care Nursing Innovation project in Auckland city received government funding in 2005 of $\$ 750000$ over three years (PHCNIET, 2007).It was one of eleven new primary nursing projects funded by the government. This innovation was aimed at developing and strengthening the nursing workforce and infrastructure by supporting workforce development through education and collaboration across the healthcare sector. It would also enable the identification and development of strategies within the community that would address healthcare disparities. There have been many achievements within this project to date which has being deemed highly successful and to be working in line with the Primary Health Care Strategic objectives. Goodman and Lynch (2007) outline some of the accomplishments within this innovative project. A Primary Health Care Nursing Team was established consisting of a nurse leader, clinical nurse specialists and educators to address the focus of the Primary Health Care Strategy. Nurse leaders were also appointed to Maori and Pacific health Primary Health Organisations to address specific health care inequalities suffered by these groups. Clinical Training Agency funding was accessed to support the development and training of nurses particularly in the areas of chronic care management. The team have been involved in the scoping of the Primary Health Care Nursing Scoping Project which supports the involvement of nursing care along the entire patient continuum of care. Another project under this innovation involves the scoping of all nurse-led services in this DHB. Multiple strategies have been embarked on to address 
healthcare disparities at different levels and this innovation project is a prime example of the government's commitment to the health of its population and its goal of collaboration for mutual benefit. It is also an example of how the service and the community have intersected to deliver on the goal of reducing the burden of illness.

\section{Conclusion}

This case is made up of many parts located in context and could be likened to the multiple threads intertwined and linked to weave a piece of fabric. The nurse-led clinic did not develop in isolation but as a direct result of intrinsic and extrinsic forces. The context of this case is important in view of the socioeconomic determinants of health and the implications of market forces on the way our services are constructed. This case is also important in view of the practice implications for the nurses who are delivering chemotherapy in this setting. New Zealand's healthcare system is undergoing rapid changes in response to political influences, monetary constraints, and the challenging needs of its population. It is not economically viable to have specialist oncology centres located in areas with a low population density, hence the need for relationships between regional services aimed at providing appropriate and equitable access to care. The development of new models of nursing care is seen as one way of addressing care gaps. These current and future developments will not be without obstacles and perceived threats. However, these changes represent exciting and challenging times for nurses in New Zealand and will enable the development of lines of nursing practice that are unique to the New Zealand context. In Chapter Three I position the case in its wider context and provide a review of the literature in relation to the changing nature of cancer care. These lengthy threads of influence continue to shape and influence practice within all healthcare settings and to understand this case is to position it amidst its contextual influences. 


\section{CHAPTER THREE: A LITERATURE REVIEW - WEAVING THE STRANDS}

"Weave - to move from side to side whilst going forward" (Collins et al., 2006, p. 838)

\section{Introduction}

The delivery of cancer care is constantly evolving in response to evidence which means that local delivery is also constantly evolving. In this chapter I continue to develop and weave the strands that form the basis of this case study by clearly locating it in the context of wider influences. Internationally changes within the cancer care setting are occurring rapidly and New Zealand has not been exempt from these forces. Nurses locally and nationally who manage delivery of chemotherapy treatments in the outpatient setting are anecdotally known to indicate that they enjoy this evolution of knowledge and those who have been in practice for some time can relate the development of their practice through eras of drug regimens and protocols. They keenly observe the outcomes of such agents and in some cases have been involved in clinical trials to test such protocols. These nurses also recognise the impetus behind such changes have come about through global forces, for instance, from drug companies which impact on technological influences. New ethical challenges have also arisen within the practice setting amidst escalating scientific knowledge and this in turn has challenged traditional ways of practice. Many patients are well read on their disease process and possible drug trials and there are demands for models of care that are responsive to their unmet needs; for example that of counselling and support and education at different stages of the illness. Nurse are well aware of their role in contributing to patient's quality of life and the role they have to meet with the growing needs of the patient as health consumer. These aspects of the role 'chemotherapy nurse' are not necessarily indicated when the nurse achieves accreditation to be a primary caregiver in this treatment, but the ability to conduct conversations about the nature of the drug and the potential outcomes sit alongside knowledge on the toxicity effects and safe handling. The nursing role does not extend in New Zealand to prescribing 
chemotherapeutic agents however in this setting the nurses are the immediate health professional at hand and in the case of an emergency are able to deliver first aid if required.

In line with the conceptual framework developed for this study (see Chapter 4, Figure 1). I wanted to locate this case amidst the context of global forces. In the previous chapter I positioned the case is relation to its local and national context and outlined some of the changes taking place within the New Zealand healthcare environment. This chapter further advances that exploration and examines the global changes as they impact on the cancer care setting, the relevance of nurse-led models of care and the place of chemotherapy delivery in the discipline of nursing. I refer to the literature to inform this inquiry and to provide insights into the extrinsic influences that impact on this setting and the challenges nurses face administering chemotherapy in rural areas.

\section{The changing nature of cancer care delivery}

Cancer care has emerged as a global concern. Future estimates maintain that 10 million deaths will occur on a yearly basis from cancer around the world by the year 2020 (Jones, Chilton, Hajek, Iammarino \& Laufman, 2006). The fiscal constraints and consumer demands forced on the healthcare environment has meant that healthcare systems have had to change towards delivering models of care that are economically viable, and are appropriate and responsive to patient needs. The impact of these changes has affected the way care is delivered across a variety of clinical settings both abroad and in New Zealand (Buchsel \& Glennon, 2005; Kearney, 1999; Macduff, Leslie \& West, 2001; McCaughan \& Thompson, 2000). Prolonged hospital admissions are no longer considered appropriate and most patients receive their cancer treatments in the outpatient setting (McCaughan \& Thompson; Moore, 1997; Parish, 2000). Significant advances in cancer treatment modalities combined with increased technology have also impacted on the way treatment is carried out. Other factors driving these changes are; an increasingly elderly population, greater numbers of patients with chronic disease, increased patient acuity, and the fact that traditional ways of caring for patients is no longer adequate or appropriate (Buchsel \& Glennon; Loftus \& Weston, 2001). Nurse-led 
clinics have evolved as a prime example of an alternate model of nursing care developed to meet some of the challenges posed by the current healthcare system (Buchsel \& Glennan; McCavana, 2000; Wiles, Postle, Steiner \& Walsh, 2001). Nurse led clinics (NLC) have not developed without a degree of ambivalence and mistrust (Fitzsimmons et al., 2004). This in part is suggested to be due to prevailing medical attitudes and whether the clinics are perceived as positive or threatening and whether they are proven effective (Loftus \& Weston).

\section{Nurse-led clinics}

Despite a mixed consensus towards supporting this model of care, there is a growing trend towards the development of NLC's and the development of nurses in clinical leadership roles to manage these clinics. The roles are described as advanced nurse practitioner roles in cancer care (Buchsel \& Glennon, 2005; Corner, 2003; Cox \& Wilson, 2003; Egan \& Dowling, 2005; Kearney, 1999; Loftus \& Weston, 2001; Moore, 1997; Parish, 2000). New models have arisen to address care gaps and nurses have responded in positive ways to these challenges. The New Zealand Primary Health Care Nursing Innovation Projects (2007) are prime examples of how nurses have responded to the challenges brought about by this new paradigm within healthcare. There are many different models of care all falling within the boundaries of NLC's. Some models involve the extension of nursing roles which has seen nurses subsume roles and tasks that were previously the domain of doctors. Other models have enhanced and developed the nursing role with nurses functioning as autonomous practitioners developing distinct lines of practice.

In response to these different views, attitudes towards NLC's continue to vary. Moore (1997) views NLC's as a supportive model of care developed primarily to address the unmet needs of the patient, whilst Egan and Dowling (2005) describe it as a service providing an interface between nursing and medicine. They maintain that this service is run by nurses who have taken on previously held doctor's roles and tasks. An accusation of 'doctor nurse substitution,' is an alternate viewpoint put forward by Corner (2003) 
and Wiles et al. (2001) who suggest that the nurses are being used to address doctor workforce issues.

I suggest that competing tensions will remain amongst consumers and healthcare professionals alike as to the positive and negative benefits of NLC's. This is due to complex issues such as: the type of model instituted; the roles the nurses play; the context in which the clinic develops; plus prevailing medical attitudes (Corner, 2003; Fitzsimmons et al., 2004; Moore, 1997). In the United States of America advanced nursing roles are commonplace and have been an accredited training for a number of years. However, in some parts of Europe and other countries the resistance to NLC's is high. Corner's rationale again suggests the reasons are complex: it could be high doctor patient ratios; or the perception that this model is not necessary; or concerns around the educational preparedness of nurses to take on this advanced role.

In a review of the literature to evaluate the impact of nurse-led follow up care, Cox and Wilson (2003) found that this type of care was favoured by patients and proven to be an acceptable and feasible model of care. However they cautioned that the effectiveness of NLC's across a range of specialties is still to be proven and remains a subject that requires further study. A report by Parish (2000) on a randomized trial comparing traditional medical follow up care versus nurse-led care interestingly found that patient satisfaction was high in both services. However, a key factor to emerge from the group in the nurse-led clinic was the value placed by patients on the prompt access to the nurses and the time spent listening to their problems. These findings are consistent with a quantitative study by Egan and Dowling (2005) who found high patient satisfaction rates with care in a rural nurse-led oncology clinic. Corner (2003) suggests that whether nurse-led care is acceptable to patients as opposed to doctors' advice and treatment is still a factor that requires further clarity. She indicates that a lack of professional development and a degree of resentment that (they the) nurses are being used to address current doctor shortages could be a factor why some nurses do not want to embrace these advanced roles. 
The inadequacy of traditional models of care versus the increasing need for cancer care presents a challenge in today's healthcare environment (Parish, 2000). Whether NLC's are a cost efficient answer to addressing the increased cancer care burden remains to be proven (Moore, 1997). Fitzsimmons et al. (2004) share this view point and suggest that nurse-led clinics should not be viewed as the only option in relation to future chemotherapy delivery services. The role of the nurse in the oncology outpatient setting is an area that still needs further research (Eagan \& Dowling, 2005; Fitzsimmons et al.). A difficulty in evaluating these services for future planning stems from the fact that there are different models of care located within different specialties all falling under the rubric of nurse-led care. This means that although a particular model may be effective that assumption should not be generalized to another nurse-led model of care. These models of care have evolved to meet specific patient needs and in some instances in response to fiscal and resource issues. The impact of this model of care on the development of nursing has also highlighted many concerns over the professional development of nurses to take over this role. Corner (2003) clearly has indicated that not all nurses embrace this concept and not all nurses want to be engaged in ongoing study. In some situations this type of model is perceived to be threatening to the professional dominance of doctors. However in contrast, the rural setting necessitates nurses evolve their practice to meet the challenges of providing care in an environment with fiscal and contextual constraints. Many rural services rely heavily on the nurse to deliver care. This NLC model of care has worked successfully in this rural region of New Zealand and will continue to play a role in future care delivery. However ongoing professional development, workforce specialization combined with activities that promote research are crucial components of practice if nurses working in these areas are to ensure appropriate care delivery and sustainable outcomes (Buchsel \& Glennon, 2005; Fitzsimmons et al; Kearney, 1999; Loftus \& Weston, 2001; Mooney, 2001; Wiles et al., 2001). 


\section{Characteristics of chemotherapy practice in rural areas}

The factors that necessitate the need for skilled health professionals who support the patient during the patient journey recognise the turbulent time the patient is experiencing. They recognise that the patient is probably regarding their diagnosis as life threatening. Cancer remains the second highest cause of death in New Zealand and the numbers of people expected to develop cancer each year is expected to increase in line with global trends (Ministry of Health, 2003a). Newly diagnosed cancer patients are faced with many treatment options and decisions against a background of significant emotional stress and attempts to make sense of the new information they've been given (Hoelz, Sladek \& Michaelson, 2007; Wilkes, White \& O'Riordan, 2000). They may be familiar with terms such as radiation and chemotherapy but may have little understanding of the impact of these treatments on their lives. Chemotherapy will be used as a treatment modality for significant numbers of these patients, both those with acute disease and those who are palliative. To deliver what is most appropriate for each patient the treatment is tailored very specifically by dose, and timing by the oncology specialist team. (McCaughan \& Thompson, 2000; Schulmeister, 1999). The age and severity of the disease and the patient's experience of the treatment will all be taken into consideration as the treatment continues. Chemotherapy nursing practice therefore occurs as part of a team of experts and requires the utilization of a vast array of organizational and clinical skills and expert knowledge; all being cognisant that care is taking place within an environment characterized by rapid changes in treatment methods (Gilbar, 2001; Lasselter \& Warnick, 2003; McCarthy et al., 2003). The majority of chemotherapy is now given in the outpatient setting by nurses because chemotherapy drugs by nature are considered toxic and have the potential to cause numerous side effects (Gilbar, 2001) this knowledge is integral to the nurses' practice. The nurse recognises that the patient having chemotherapy is vulnerable in multiple ways throughout the disease trajectory. At the first level of organising the assessment obviously the nurse is always thinking about the patient's quality of life and takes into account a range of criteria such as: the impact of the disease; the place where treatment takes place; treatment schedules; drug toxicities; and chemotherapy related side effects. 
Errors made at any point from the work-up to treatment, during the writing and ordering of drugs, to the administration and ongoing management of treatment can have serious consequences for the patient (Tanghe et al., 1996).

A chemotherapy regimen may consist of one or several drugs each with their own narrow therapeutic range. These drugs come with an array of side effects and when used in combination the potential for adverse effects is amplified. The toxic nature of this class of drugs is considered critical and a concern for all practitioners who are involved in the prescribing and administration of chemotherapy that error is avoided. Although medication errors can and will occur in any practice setting the potential for errors to occur in rural environments is amplified due to several influences. These include distance from specialist input, the practice context, inadequate resources, staffing skills, appropriate education, including logistical issues obtaining treatment drugs and timely blood results (Gilbar, 1999, 2001; McCarthy et al., 2003; Tanghe et al., 1996; Wholey, Moscovice, Hietpas \& Holtzman, 2004; Yates et al., 2003).

A high probability of errors was indicated to be highly possible as the result of a retrospective study by Gilbar (1999) who audited the drug records of patients receiving chemotherapy who were referred from main centres to a base hospital (which might be considered similar to the setting where I was researching practice). This research report suggested a series of errors occurred for instance: in documentation; in unclear or absent information; or in ambiguous instructions that created a high potential for misinterpretation. In a later study Gilbar (2001) maintained that the most important reason that medication errors occurred in this type of setting was due to the fact that information about the patient and the medication were not always available when required. I will indicate later in the paper that I found these research findings highlighted similar situations.

I was made more sensitive to these nuances in the practice setting through research findings which indicate that the problems of establishing safe delivery of chemotherapy are universal. The context within which rural nursing practice occurs can present many 
obstacles that interfere with safe chemotherapy treatment as suggested by the findings of a survey by McCarthy et al. (2003). Some of the problems encountered which require nurse planning were as follows: the infrequency of treatment schedules to maintain competency; no dedicated chemotherapy spaces; and inadequate information arriving with the drug orders to enable safe management of side effects. This study suggested that exposure to issues impacting on patient and nursing outcomes is a way toward improving a service and the standard of care provided. These findings support previous studies and confirm that the potential for poor patient and nursing outcomes are high in rural practice settings due to multiple influences. However, the opportunity to strive for high quality in the service through education, training and auditing of the processes alongside system development was obvious.

Nurses in rural areas play a major role in patient care and in order to best meet and understand their patients' needs, they become attuned to and responsive to the issues that influence and affect their health. Gaining new skills and the desire to provide comprehensive cancer care for their patients is a challenge rural nurse's readily embrace (McCarthy et al., 2003; Rosenberg \& Canning, 2004). Challenges in delivering safe and consistent care are also hampered by the distance patients live away from treatment centres, the supportive networks they have in place and the knowledge held by the healthcare professionals looking after them (Bushy, 2006).

\section{Conclusion}

This chapter has focused on the nature of cancer care delivery in response to socioeconomic influences and the fact that traditional models of care are rapidly being replaced with ones that appear to be responsive to patient needs. Nurse-led clinics are described as one way of bridging the gaps and improving healthcare outcomes. However, the effectiveness of the clinics is debated by other professionals. This research intends to describe the specific challenges rural health care providers face when providing chemotherapy treatment particularly when faced with contextual, fiscal and resource constraints. While research indicates that the potential for medication errors 
and poorer outcomes is amplified in less controlled environments, the research will consider if this is in fact evident in this case study.

The literature in this chapter talks about balance but the fulcrum where the decisions are made when the patient is present in the rural setting often come down to the decision making of the nurse. Whilst practicing as the oncology nurse with concern to engage as a peer and offer education to colleagues from my wider experience, I found that I faced many challenges on a day to day basis just to maintain consistent care and to promote good patient outcomes. I used the case study research as an opportunity to articulate my own narrative and will indicate how this contributes to the trustworthiness of the overall study. These wider threads are the basis of the influences that drive change within our healthcare setting and in turn influence the way care is woven across the healthcare continuum. The focus of the next chapter four is on the research methods employed by the researcher to undertake this case study of practice. I present a strong narrative voice in chapter five in order to show the link between knowing that negotiating care is an ongoing fight and balance between healthcare resources and situational influences which often are out of one's control. 


\section{CHAPTER FOUR: DESIGN AND METHODS OF INQUIRY - THE STRENGTH OF THE FABRIC}

“Strength - the quality of being strong” (Collins et al., 2006, p. 742)

\section{Introduction}

In this Chapter I discuss the design and methods of inquiry applied to the case. The study design, methods of investigation and the process of data analysis were important to the case and to me as the researcher in that it would allow the case to stand as a credible piece of research. It is these qualities I believe that contribute to the strength of this research. The research is focused on the nature of chemotherapy practice in a rural practice setting and the issues the nurses indicated impacted on their practice. A descriptive exploratory case study design was developed to capture the range of qualitative data to explore the multiple viewpoints and perspectives of the nurses in the chemotherapy clinic. The design allowed real life investigation into the question under study. The established understanding of a case study as methodology was most useful as it was like a strong fabric which allowed for rich description.

The case study as a research strategy was considered appropriate to illuminate the topic of nursing delivery of chemotherapy in a rural setting because there has been no research on this subject within New Zealand and little internationally. Within this chapter I will discuss the research methods undertaken and explain my rationale behind using this approach to explore the research question. The discussion will encompass the study design, conceptual framework, the ethical considerations relevant to the study, data collection methods and the process of analysing the information gathered. I will also integrate issues of how trustworthiness, rigor and validity of the study were maintained along with the limitations of the study. I also provide a reflective account of the difficulties I encountered during this phase of the research project. The strength of this fabric - the case - rests on the design, the methods employed, acknowledgement of the challenges encountered and the steps taken to minimise these difficulties. 


\section{Rationale for using Case Study Methods}

The work of Yin $(1984,2003)$ and Stake $(1995,2000)$, the chief proponents of case study methods have informed this work. My decision to use this (form of) research method was driven by a number of influences. My engagement to work alongside my peers as a Clinical Nurse Specialist to enable practice development provided what I believe to be an ideal opportunity for us to gain insight and knowledge into this unique practice situation. My attempts to uncover any existing research into rural nurse chemotherapy practices in New Zealand were unsuccessful, so this case (in essence) could be taken as a starting point for future empirical forms of inquiry in New Zealand into this subject. Secondly, because the nature of case study inquiry involves looking into the multifarious nature of a situation within its context, with regard for the subjective experiences and meanings uncovered, further increased its appeal to me. The case study would allow my colleagues and I to uncover the issues affecting practice and in turn provide a vehicle for the voices of my peers to be heard. Thirdly, the use of case study methods appealed to that inherent part of me that loves to delve and uncover a good story. Nursing has a long history of oral traditions and passing on information through story telling and from my experiences I believe it is an activity that is enhanced by rich description which in turn tells the tale of the unfolding drama of human life. I liked the idea of investigating multiple viewpoints of the case to create a portrait which would stand and be credible and convey what it's like to be a nurse in this practice setting.

\section{Case Study: A Methodology within the Qualitative Paradigm}

Case study methods are a research strategy and the phenomenon under scrutiny is defined as the case (Yin, 2003). The phenomenon of chemotherapy practice located in a rural base hospital was able to be studied using case study methods. The literature maintains that as a research strategy it lends itself to new research of real life situations where not much is known about a subject (Graziano \& Raulin, 1993; Pegram, 2000; Sandelowski, 1996). As a form of empirical inquiry in qualitative research its application has become increasingly widespread as more and more disciplines utilise this method to investigate phenomena (Stake, 2000). Case study research methods can sit 
within the quantitative or qualitative paradigm. However when one considers the definition of case study methods, which are according to Yin (2003) is an investigation of a phenomenon in real life context with its meanings and experiences, it appears to sit firmly within the qualitative paradigm. This form of empirical research at times does utilise quantitative data to provide additional information to inform the subject under study.

Research types such as phenomenology, ethnography, grounded theory, and biographical studies all fall within the qualitative paradigm (Hancock \& Algozzine, 2006). Qualitative research strategies are aimed at creating better understanding of the different dimensions of the human experience and subjective meanings (Liehr \& Marcus, 1994). The experiences we bring to this thing called life are coloured with our different viewpoints and perspectives of what we believe to be our reality. It is these qualities say Pegram (2000), that allow us to understand what we know as our world and qualitative methodology is the vehicle we use to enter into this landscape. The researcher's role in real life investigations is that of being an essential tool to collect information from the different sources to piece together a picture that explains the subject under review (Liehr \& Marcus). Criticisms of qualitative methods in research are usually directed at perceived researcher bias, a lack of reproducibility, generalisations and the huge amounts of information garnered from small sample sizes. In response to these criticisms Mays and Pope (1995) contend that whilst all research is selective the different methods employed to collect information all have their own inherent strengths and weaknesses. Furthermore, how are we to study human behaviour in a real life context fraught with its dramas, if we do not employ qualitative methods? This research design was strengthened by keeping an audit trail and records of data collection methods which included detailed notes of the data analysis process and the way interpretations were reached. Participants also provided verification and feedback on the outcome of the research to ensure that the researchers account best represented their viewpoints. One advantage of using qualitative strategies is that it is useful when seeking the gestalt or emergent holistic picture of chemotherapy practice in this setting. 
Case study is a method of inquiry and according to Yin (1984) its intent is to find out more about a subject. The subject of that inquiry he maintains is the case which is made up of many parts and which is investigated within context. Stake (2000) provides a slightly different viewpoint in that he contends that case study is not so much a methodological decision but a choice to study something and that when we exercise that choice we are in essence studying a case. What sets this case apart, what makes it unique, are questions that should drive the focus of the inquiry allowing the researcher to get to a point where they can truly say I know the case well (Stake, 1995). This case delves into chemotherapy practice issues by a group of rural nurses and our investigation sought to uncover the unique and particular elements that contributed to the function of the case. Yin (2003) recommends that the case study researcher draw up a predetermined template as a guide to what should be investigated within the case. $\mathrm{He}$ maintains that the additional purpose of this template would allow boundaries to be set to limit the study. To address this I developed a list of issue statements and questions prior to the research identifying a range of topics that I would consider, providing a complete description of the essence of this practice setting (see Appendix A). The flexibility of case study methods and the utilisation of different techniques to gather evidence are key characteristics that allow a complete picture of the phenomenon under scrutiny to emerge (Lincoln \& Guba, 1985).

As a research approach case study methods are not exempt from criticisms and part of the problem could be the fact that a case study can be about an individual, group, organisation, event or outcome. Also terms such as case study, review, report and management are used loosely therefore it's not surprising that some degree of ambivalence exists towards this methodological approach. The root of these criticisms rest with researchers who use less rigorous research techniques, have not clearly defined their case and wider concerns that case studies are considered in evidence based modelling but provide little basis for scientific generalisations (Bergen \& While, 2000; Pegram, 2000; Yin, 2003). Yin is however clear when he asserts that it is not possible or advisable to make generalisations from a single case or experiment and then apply these to other situations. The only generalisations allowed within this methodology he 
proposes should be those of a theoretical nature however readers can make their own comparisons and judgements based on their understanding of the data. This case is about what sets this practice apart and my intent was never to generalise it to other settings because contextual variables in other settings are dissimilar. There are several types of case studies however Stake (2000) outlines three main types. He firstly identifies an intrinsic case study which is embarked on because of its interest factor and the researcher wants to gain a deeper understanding of the subject. He secondly identifies an instrumental case study where the focus of the inquiry is insight into an issue; the case is of secondary importance to the main intent which is to understand something else. In the next section I give two examples of instrumental case studies where this aspect is demonstrated. Thirdly Stake identifies a collective case study approach whereby several cases are jointly investigated to understand a phenomenon. These cases are studied collectively to lead to better understanding of a particular issue. In the case of instrumental and collective case studies these cases do make generalisations. This appears to be in contrast to the stand Yin (2003) takes on generalisations and this can be confusing to novice researchers, which is where I firmly place myself. I believe that my case has a high interest factor and I locate it firmly within the category of intrinsic case study and I present it so that it can be read as a subject worthy of interest.

\section{Applicability of Case Study to Nursing Research}

Case study methods are and have been increasingly employed by other disciplines such as sociology, medicine, psychology, law, business management and education and it has its origins in the social and behavioural sciences (Yin, 2003). The use of case study methods in nursing could be said to be somewhat in its infancy and one indication of this according to Bergen and While (2000), is that up until recently nursing research texts have paid little attention to this empirical form of inquiry. The flexible and diverse nature of nursing practice (which) is ever unfolding and could best be described as occurring in the 'here and now,' making it a suitable subject to which case study research methods can be applied (Pegram, 2000). There are indications both in New Zealand and abroad of the increasing use by nurses of case study research methods. The advantages of using this approach can not be understated and its potential value to 
nursing is immense. It allows the study of contemporary practice in real life situations, employs many methods to gather information and locates the person and their experiences as central to the case (Ammenwerth, Iller \& Mansmann, 2003; Bergen \& While, 2000; Smith \& Topping, 2001). In my research the case study approach was the best fit because it allowed me to do all of the above and to also explore my role within the case.

In order to demonstrate the value and applicability of case study research to nursing I outline a few examples of its use nationally and internationally. These cases also demonstrate the multiple methods used to inform each study and how particularly in instrumental case study the primary focus of an initial case can change as the investigation uncovers previously unrevealed relationships or new information. There appear to be increasing calls within the nursing literature for nurse researchers to utilise case study methods as an alternative to other traditional approaches to descriptive study (Bergen \& While, 2000; Smith \& Topping, 2001; Zucker, 2001).

Sims (2004), a Masters student with Victoria University of Wellington, employed case study methods in her study into the benefits of a New Zealand Nursing Undergraduate Clinical Education Model. She identifies her research as an instrumental case study which is undertaken to facilitate understanding of something else. In line with a mixed method approach of collecting data she sourced information from organisational records and conducted interviews with key informants to create a bigger picture to inform the study and to establish validity. What emerged from this study was a description of a multifaceted role of the undergraduate Clinical Nurse Educator (Sims).

Similarly an overseas example of instrumental case study research in nursing is the Smith and Topping (2001) study. This study evaluated the impact of staff participation in a Neuroscience Course and the perceived impact by practitioners of that education on their practice. This course was instituted in response to an educational needs analysis of nursing staff working in a children's ward which identified a number of areas where ongoing education and training was needed. Data was collected from interviews, self 
report evaluations and performance assignments and eventually used to fulfil the research objectives. The findings of the study demonstrated a positive relationship between participation in the educational programme and the ability of the nurses to provide improved care. According to the researchers the advantage of using this methodological approach was that it allowed exploration of relationships in practice, individual interpretations and uncovered hither to unnoticed connections within the case.

The Ammenwerth et al. (2003) study is yet another example of the application of case study methods in nursing research. This study utilised quantitative and qualitative techniques to evaluate a computer-based nursing documentation system in four hospital wards. This was not the primary focus of the case whose real aim was to ascertain the benefits of applying triangulation techniques to this form of evaluative research. When the data was gathered from its many sources it was collated to confirm the results and to also highlight what new information had been uncovered. The results of this study showed that triangulation techniques utilised in a case study were of immense benefit when used to confirm results from different parts of the study and to validate the research. This case is not only an example of employing case study as a research strategy; it could also be termed a collective case study because it involved the joint study of four different areas. This case also highlights how nursing can successfully incorporate techniques from both the quantitative and qualitative paradigms to promote rigor and validity thus ensuring that case study methods can stand equally with other forms of inquiry as credible and worthy of note.

\section{Study Design}

This study took place in a rural New Zealand area where the researcher worked for a period of thirteen months as the Oncology Nurse Specialist involved in the coordination and administration of the nurse-led chemotherapy clinic. Data to inform the context of the study was obtained from a review of existing literature, service and organisational documents plus observation of the clinic and nursing practice. The three nurses working in the chemotherapy clinic were interviewed to gain their perspectives on practice issues. Permission was sought from the ethics committee to also interview the previous 
oncology nurse who was on leave at the time of the study and who had returned temporarily to the area. She was a relevant source of information as she had been instrumental in the development of this service. The researcher participated in the study as a participant observer providing the unique viewpoint of being inside the case and who was familiar with the practice and processes involved with chemotherapy. Excluded from the study were the two nurses involved in distant chemotherapy practice at another rural hospital in the region. This was because of their limited range and scope of chemotherapy practice. These nurses may not administer chemotherapy for weeks or months on end.

A sequence of logical steps was undertaken when developing this case study. Step one involved the researcher collecting as much information as possible about the case, the service, its activities, clients and contextual setting. This was in line with Yin's (2003) recommendations to compile a list of topics to be investigated within the study which will in turn provide a holistic account of the subject under investigation. The data was derived using multiple methods such as the examination of organisational records, review of documents, and observation of the practice setting, and interviewing key participants who worked in the clinic. The second step involved organising the information into an approach that highlighted the focus of the study. Whilst reviewing documents the information was organised into chronological order outlining how the clinic evolved, the impetus for development, and its current state. All the data I gathered was summarised for key information, concepts and themes which then resulted in a descriptive account of practice that tells the story of this case. The next step involved validation of the research account by research participants. This was to establish if the account written by me the researcher accurately depicted participants' perceptions of the issues under study. In the next section I discuss the conceptual and theoretical framework which informed the case; the baseline on which this case stands. 


\section{Conceptual and Theoretical Framework}

The direction, structure and boundaries of the study are supported by a conceptual and theoretical framework in line with Yin's (2003) recommendations to researchers embarking on case study research. This framework provided me with a focus and plan in determining what information to collect and provided an additional means of strengthening the validity of this research. The conceptual and theoretical framework in figure 1 outlines how the case was organised within its context and the map I used to position data I collected as evidence to inform the study. I had in-depth exposure to the practice environment and, based on my experiences, I developed two theoretical propositions to assist me with the direction and focus of my investigation. A proposition is defined as a statement or even a suggestion whereas a theory can be a set of ideas to explain something or a hypothetical statement (Collins et al., 2006). These definitions appear to be similar and appear confusing when they are used interchangeably. In terms of these definitions it would be reasonable to say that a theoretical proposition is a hypothetical statement. Similarly a concept is defined as a general idea or could also be a hypothesis (Collins et al.). In developing these propositions I'm making hypothetical statements that firmly position the focus of the inquiry of the case. This positioning created structural scaffolding that ensured that I made links between the data and propositions to either support or refute them within the course of the investigation. Overall, this scaffolding ensured that I stayed within the boundaries of the case as my attention was directed to reveal something worthy of investigation in the course of the inquiry.

The first theoretical proposition I developed sought to examine how the survival and support of chemotherapy practice in rural areas was grounded in mutually beneficial relationships fostered by contextual influences in and around practice.

The second theoretical proposition sought to test my assumption that if attention was paid to developing a nurse's knowledge and skills, whilst providing her with access to appropriate resources; these would provide the rural patient with greater protection and improve chemotherapy outcomes. The underlying assumptions guiding these statements 
and links to the data collected will be examined and discussed in chapter seven in light of the findings of this study.

The conceptual framework clearly identifies the case and is informed by a list of issue statements, questions and theoretical propositions developed prior to collecting information. The case is examined within its context at multiple levels. These include the immediate practice environment, the organisational level and national context together with the position of this case in relation to the discipline of nursing and associated theory. The links between the data sources used to inform the study, the context and the case are clearly shown within this framework. This process is made explicit in Figure 1.

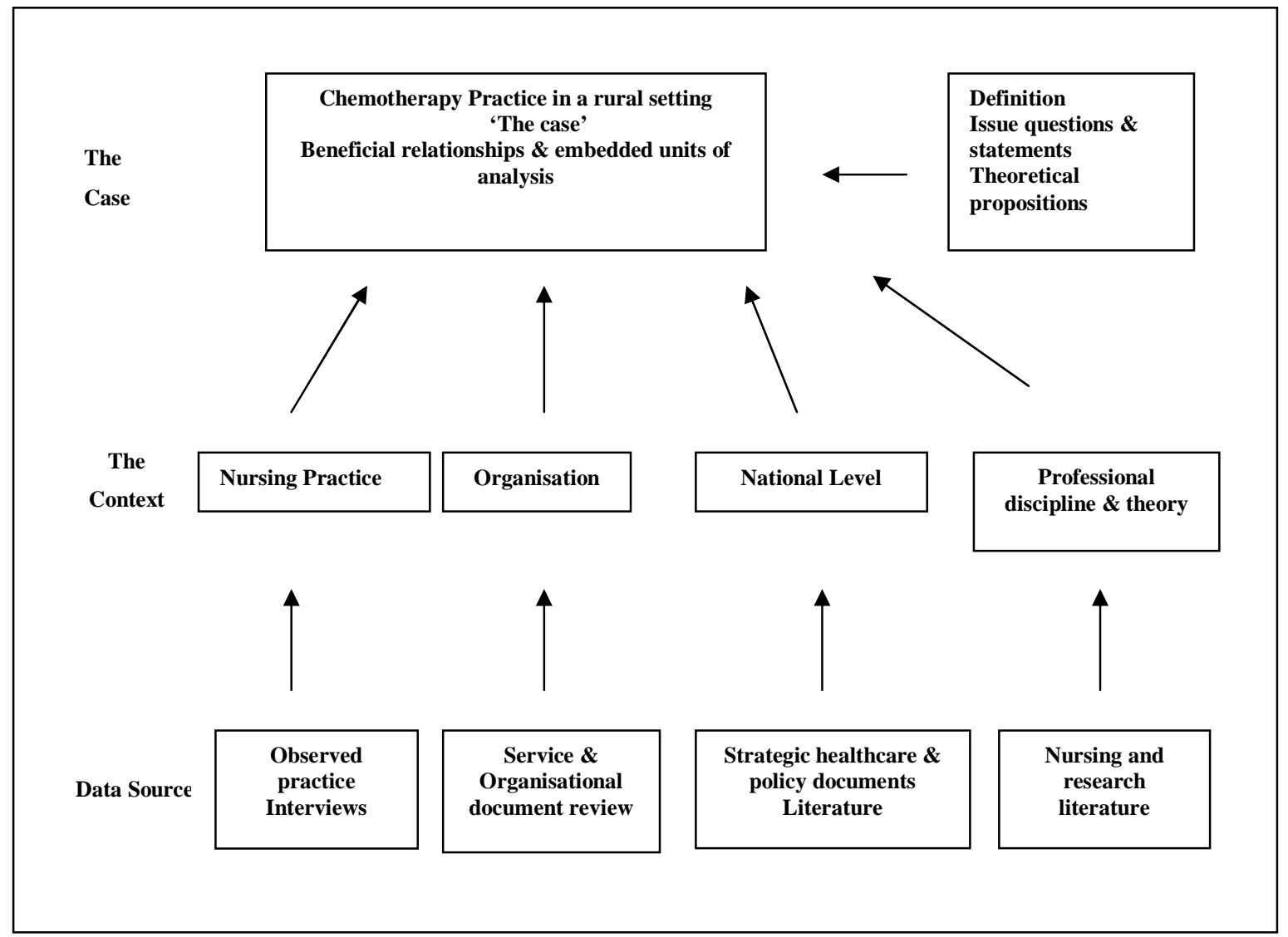

Figure 1: Conceptual and theoretical framework: the case, context and multiple data points 


\section{Ethical considerations}

The ethical considerations relevant to this study are outlined in this section. Permission was sought and received from the District Health Board where the clinic is situated and the regional ethics committee to carry out the research. Participants were identified and approached in writing inviting participation in the study. Documentation about the study and its aims and objectives and what the study involved for participants were outlined in the information provided to them (see Appendix B). A consent form outlining voluntary participation in the study was signed by participants before the research commenced and they were informed that they could withdraw at any time from the study if they so wished (see Appendix C). To preserve participants' anonymity, identity and place of work, names of people, places and location are not referred to in this study. Also any references to literature that could identify this place and its people are not referred to in this work. Due to the special relationship the participants had with the researcher and their collegial role, confidentiality agreements were an additional protective measure enabling discussion about being participants in the project; they were signed by participants prior to interviews and clinic observation sessions (see Appendix D). Participants were also given the opportunity to verify the information they provided and to say what information could not be used in the study. A key issue to emerge out of the ethics application was the issue of gathering of information during the observation of practice without the knowledge of patients in the clinic at the time. This was overcome by telephoning patients the day before treatment to inform them of the research and giving them the opportunity to read the study information sheet. All patients who were contacted and were receiving treatment at the time observations were carried out for research purposes, consented freely to the observation of nursing practice relevant to their treatment.

\section{Data Collection and Method of Analysis}

This section on data collection and analysis methods is reported concurrently because as information was gathered I began the analysis of the research. I needed to understand this case from the viewpoints of the other nurses working in the clinic and wanted to 
capture their subjective experiences and the meanings they assigned to these. I observed nursing practice in the clinic and carried out semi-structured interviews to delve into the issues that cried out for attention in the case. A research journal was kept and key organisational documents pertaining to the study were reviewed. I also observed the practice setting, its site, situation and context. These multiple methods were utilised to acquire the evidence necessary to build a holistic picture of the nature of chemotherapy practice in this setting. Entering the study with a list of issue statements and questions that represented a range of topics to be investigated enabled me to keep the study focused on the important issues within the case. It also ensured that the data collected was manageable and created a boundary around the limits of the study. Yin (2003) talks about boundaries within case study research and he maintains that researchers who don't set these run the risk of collecting vast amounts of information with no clear definitive purpose as to what they will do with that information. He further states that it's impossible to investigate everything about a specific subject hence the need for a clear definitive purpose to the investigation. A predetermined flexible list of interview questions was also made available to participants prior to interviews (see Appendix E). The use of multiple methods to collect information about a case provides a means of ensuring that the rich descriptive account that emerges encompasses the reality of those involved in the case (Erlandson, Harris, Skipper \& Allen, 1993; Hancock \& Algozzine, 2006; Yin). If only one source of information were used to make this case there would be an incomplete picture of practice. Within this section I choose to briefly discuss the methods used to gather evidence to inform the case and the analysis process I used to advance the inquiry. Document review, participant observation and interviews were the main tools used to build a picture of this practice; these methods combined together further strengthen the validity of the research.

\section{Document Review}

Organisational documents pertaining to the chemotherapy clinic were examined in order to gather background information about the case. I selected the documents based on their relevancy to the issues under investigation. Part of that investigation focused on answering key issue questions such as the impetus for the development of the clinic, 
key advocates, funding and the wider socio-economic influences driving change within this organisation. The analysis and review of documentation is a common method used by case study researchers who gather information from many sources which is then summarised and interpreted to understand the research (Hancock \& Algozzine, 2006). Excluded from this document review were medical records or notes containing personal patient information. I read the documents through first to ascertain their relevance to the study. Selected documents were then read through a second time with key information highlighted. A process of ongoing reading and summarising of information occurred several times and the information extracted was then used to provide literal answers required to inform the study. Although documents are a valuable source of information and at times are easily accessible, they may also contain errors, discrepancies and record bias according to the author of the document (Grey, 1994). In this study I was satisfied that the literal information provided by the documents reviewed supported the information gathered from participants who were familiar with the circumstances surrounding the development of the clinic.

\section{Participant Observation}

Part of my research methodology to inform this case study included the observation of nursing practice in the chemotherapy clinic. Whilst it is obviously unstructured early on in the inquiry, observation is a powerful tool when applied to natural settings and becomes more focused as the observer develops a sense of what is important (Lincoln \& Guba, 1985). Becoming a participant observer meant that I (as the researcher) became the primary instrument for collecting and analysing the information gathered. The intent of my observation was to gain a deeper understanding of what was occurring in practice and the interactions taking place through identifying the key activities in this setting. The other intention was to provide evidence that would support or refute some of the issues raised by the nurses and provide additional information which could not be sourced through other means to build a picture of practice. The concept of participant observer did not come easily to me. I had to consciously learn to view practice critically and systematically pay attention to detail things I would ordinarily view as mundane and ordinary. It meant training myself to gain perspective or look with three 
dimensional vision. I did this by asking myself the question several times, 'what is actually going on here?' Permission to observe practice was sought before hand from participants and clients coming into the clinic so that the nurses were clear when I was observing practice. When practice breaks occurred I would note my observations and impressions. At the end of each clinic observation period I would spend some time organizing my data and reflecting on the whole process. I would also write a reflective account of what I had observed. I observed practice for set periods of time during four occasions when the clinic was held. Different aspects of practice were observed each time. For example, on one occasion time was devoted to a chronological account of the activities the nurses were engaged in and the unique things that stood out that day. The data from the clinic observations were generated by me in my role as participant observer. The text was read several times with themes, activities and events highlighted. Ongoing reading, summarising, reflecting on the data and making connections between events was a process I used to build a picture that described what was happening in the clinic. Manual thematic analysis techniques as proposed by Roberts and Taylor (2002) were used as a guide to make sense of the data. Data saturation point had been reached when I could no longer redefine the themes or categories without getting the same results (Roberts \& Taylor). Three themes were consistently identified which resonate with the themes yielded from the analysis of the interview data. These themes will be identified and discussed in detail in Chapter Six which presents the case study.

\section{Interviews}

Semi-structured interviews were held with participants using predetermined and flexibly worked questions to obtain their different viewpoints. Dependant on the answers elicited from participants additional questions were asked to probe the issues raised to create better understanding. An interview suggested (Dexter,1970 as cited in Lincoln and Guba, 1985) is a conversation with a purpose to obtain amongst many things the realities, viewpoints, concerns and experiences of participants. Similarly, Grey (1994) maintains that sometimes information can only be obtained from participants by asking them about it. The interviews were taped, transcribed, summarised and then returned quickly to participants for review and correction. 
Following the initial reading and analysis of the transcripts I contacted participants to arrange a further interview to explore some of the issues raised and in order to provide further information about the case. The transcripts were treated to Roberts and Taylor's (2002) manual thematic analysis techniques. I read the transcripts initially to get an idea of their content. They were then read through again to highlight major themes, ideas, and narrative accounts. I made notes in the margins as to my impressions and the links I was making to ideas about what I was observing in the practice. I then wrote a reflective account of each interview. The data was then treated to another analysis in relation to four key issues. These were firstly, the characteristic of practice; secondly the characteristics of the nurse; thirdly the issues that particular nurse viewed as affecting practice; and lastly the suggestions the nurse put forward to enhance practice. An important part of data interpretation is linked to understanding the characteristics of participants and their unique viewpoints as it relates to the topic studied (Smith \& Topping, 2001). This process of reading, summarising and interpreting the data continued several times as I extracted ideas, grouped and categorised themes and sub themes until I reached a point where all the categories were reduced to three major themes which proved consistent with all the data gathered from the interviews and observed practice sessions. The themes extracted from the data analysis are presented in Chapter Six which focuses on the results of the participant interviews.

\section{Trustworthiness}

This case was selected on the basis that it was representative of the phenomenon under study and it's relation to the research questions being asked. The inquiry was focused on the nature of chemotherapy practice in a rural setting and sufficient detailed description of the case is provided within the body of this thesis to create a clear understanding and explanation of this phenomenon. I believe that the case meets and satisfies the criterion which establishes it as a bona fide example of the subject under scrutiny. The fittingness of this case is linked to the validity of the study and I can assert that this case remains true to the purpose of the inquiry. 


\section{Validity}

Validity - the strength or legitimacy of this study (Collins et al., 2006) was ensured by a number of strategies. An audit trail was kept of the research process. This involved the researcher keeping a record of the research process, the methods used, details of data analysis, the decisions undertaken and the processes used to interpret the findings. This research was further strengthened by the use of theoretical propositions and a conceptual framework before engaging in data collection methods. This is a recognised technique used by some case study researchers to increase the validity of their results and to maximise confidence in the findings (Pegram, 2000; Yin, 2003). Confirmation of the research findings was done by gaining feedback from participants to see if the researcher's accounts matched participant's perceptions of the issues under study. Seeking this sort of feedback from study participants is vital in terms of contributing to the rigor and credibility of the study (Hancock \& Algozzine, 2006). The use of multiple methods to gain information about this case further provided a means of strengthening this research to accurately depict the phenomenon under study and enhance validity. This process known as triangulation uses many different sources of evidence to support the facts of a case and according to Yin is a major strength of case study research.

\section{Personal Reflection}

The process of developing the data collection and analysis was not without problems. Equipment failures were a feature affecting my first interview and I realised that some of the questions I asked were too lengthy and participants were having difficulties following the line of questioning. I solved this problem by refining my questions in the follow up interviews to hone in on the pertinent issues. I also positioned the genesis of the question. This process was indicative of my position as a novice researcher and in hindsight I should have tested my questions and prompt list with an independent colleague before the study. Two of the participants were quite nervous during their initial interviews and this affected the flow of information between us. They admitted that this was solely due to the fact that the interview was being taped and that we were in a research situation. When the tape was turned off conversation and responses flowed more easily. One of the participants opted to write a page of how she viewed the issues 
in the clinic and found this a better way to establish her viewpoint. Regarding participant observation of nursing practice, Gillis and Jackson (2002) caution that the presence of an observer may change a situation and alter the behaviour of participants so that it is unclear what is being observed. This was initially the situation in the first observation session when the nurses were a bit wary of me. However once they saw that I was not doing anything different they soon forgot the 'research hat' I was wearing for the day and continued to engage in practice as usual. There is also the issue of the likelihood of the researcher becoming a supporter of the group under study and a lack of objectivity when asking questions or viewing events from different perspectives (Yin, 2003). I entered this phase of the research very mindful of this and took pains to be objective by using critical reflective practice, and systematically journaling my impressions and ideas to maintain a sense of the bigger picture of this project. Collecting information from many sources to provide evidence to support the case was one way of ensuring the trustworthiness of this study. Being mindful of my position and collegial relationships and taking care not to collect information under deceptive means was another way of ensuring trust with my colleagues. The strength of my contribution to this research was my familiarity with this arena of practice and my in-depth knowledge of the organisational and technical issues around practice. The study was further strengthened by my past clinical experiences and my relationship with colleagues in the clinic. The insights I have brought to this case study would not have been possible if a passive observer had carried out this research.

There is an abundance of research into the role of the advanced practitioner and the clinical nurse specialist. However, when definitive statements are made (both) in New Zealand and overseas about these roles, the role of the nurse as researcher is seen as integral to this advanced practice. In fact this role as researcher is firmly embedded in these defining statements sitting alongside other role descriptors such as clinical expert, consultant and educator (Jacobs, 2003; Moore \& Sweedman, 2004; Pearson, 2002; Raja-Jones, 2002; Richardson, 2005). When I engaged in this research I was in essence fulfilling part of my role as a clinical nurse specialist engaging in research-based activities to advance nursing practice and knowledge. 


\section{Conclusion}

In this chapter I have discussed case study research methods and how its application fits within the framework of this research. It is a strategy employed in empirical research and it allowed me to understand the multifaceted nature of practice in its contextual setting, enabling the voices of the participants to be heard. I have detailed my journal as I moved through the process of designing the study, obtaining ethical approval and applying analysis and research techniques that would allow this work to stand the tests of rigour, validity and reliability. A descriptive account of practice emerges in the following chapters as the findings of this research are presented and discussed. 


\section{CHAPTER FIVE: Observing the Fabric}

"To observe - to notice or to watch something carefully" (Collins et al., 2006, p. 525)

\section{Introduction}

The purpose of this chapter is to describe the nature of observed practice through the lens of the researcher providing an indirect experience for the reader of what practice entails. Because practice changes and evolves according to internal and external influences, what is essentially described as nursing practice today may not be the practice tomorrow. However, the essence remains and this detail of the day to day practice known as the essence of practice is what the case study reveals.

A brief description of the way the service is constructed follows. The model of care delivering chemotherapy at this rural (based) hospital is nurse-led. The nature of practice is small, and the median average number of patients seen per month is eighteen. Patients are referred to the service from a large acute city hospital with specialist oncology and haematology services. This service has contractual links to this rural hospital and provides oncology and haematological support via telephone, email and monthly visits by consultants. Three nurses including the oncology nurse specialist coordinate care and deliver treatment. The nurses come from varied clinical backgrounds with a combined total of 67 years nursing experience. The clinic is held weekly in the out patient department, usually with two nurses in attendance. Sometimes chemotherapy is given more than once a week in response to patient needs, for example, a delay in treatment due to illness. A total of ten different chemotherapy regimens are given in the clinic and range from the simple to moderately complex. In addition bisphosphonates and hormone injections are also given. For those patients requiring very complex and long regimens, this usually means a trip to the specialist centre to receive care. Treatment schedules range from weekly, or to once every third or fourth week. Patients can spend a total of five to six months completing their chemotherapy treatments. The coordination of the 
clinic and its services require an array of expertise, technical skills and strategic planning. Tasks which would ordinarily be carried out by supportive administrative personnel in a larger centre are now primarily the responsibility of the oncology nurse. The following description of practice reflects the nature of practice pertinent to the period of time spent by the researcher in this area and therefore events described in this section need to be read and interpreted in light of reality being constructed in this way. In addition a brief reflective account of the researcher's experiences, including vignettes from practice will be highlighted to provide additional insights into this practice environment.

\section{The Nature of Observed Practice}

Chemotherapy practice was observed on four separate occasions. The following narrative is a descriptive account of practice which typifies the normal and unique processes that are characteristic of practice on a busy day. Imagine a fairly large room which appears small in space due to clutter from furnishings and fittings. The room is known only as the 'eye room ' as it is traditionally the place where the eye clinics are held. This room is situated in the outpatient department of the base hospital in close proximity to the accident and emergency department. This is a strategic location in the event that quick access to medical attention is required by those in the clinic. A large white recliner chair takes pride of place in the clinic and during the course of the day; nurses and patients are frequently noted to joke about who gets to sit in the chair. This chair is 'the coveted place to be in,' when having treatment due to its comfort and the fact that it is the only one of its kind in the room. The patients who arrive first derive great pleasure from being there to claim that space. The day usually begins at 08.30 hours in the morning when the nursing staff drag equipment used in the clinic out from its storage places to set up ready for treatment. The first two patients are scheduled to arrive at 09.00 hours. Additional equipment such as intravenous stands and pumps are accessed from the emergency department and other wards in the hospital. A compact disc player sits in the corner of the room playing light music to set the tone for the day. The nurses are busily involved with the usual clinic preparations, hanging up bags of intravenous fluids, checking to see that drug charts and lab results are present, going to 
the pharmacy to collect the chemotherapy and just chatting about things in general. They discover that the chemotherapy has not been dispensed in time for the arrival of the first patient. The chemotherapy is made up and ordered from the manufacturer a few hours flight away in a large city. The pharmacy department has suffered from a number of issues this year related specifically to recruitment and retention of skilled trained personnel. The impact of this delay on practice today will mean that the patients are kept waiting, treatments are prolonged and additional stress is placed on the nurses as they try to adjust the schedules and smooth troubled waters.

As today is a busy day there is an air of expectation and excitement, six patients are scheduled to have treatment, and five of these treatments are expected to last anywhere between one to two hours. Appointments are arranged with consideration to contextual and situational issues affecting the patients. For example, the distance patients have to travel to the clinic, treatment delays such as additional blood testing, convenience and whether patients in the clinic at any given time are likely to be able to engage in conversation with each other. The clinic organization is predominantly the responsibility of the oncology nurse who draws up weekly lists, schedules appointments, negotiates care with the nurses and liaises with other multidisciplinary team members. Dependant on patient numbers the clinic is usually staffed by two chemotherapy-certified nurses, one of whom would be the oncology nurse. On this day all four nurses involved with the clinic are present. They usually meet once a month to engage in ongoing education and skills maintenance within the clinic. The clinic is used as a training ground for practice development and one of the nurses is working towards her chemotherapy accreditation and is being supervised and mentored by the oncology nurse.

The day starts out messily. The nurses appear unsettled. There are frequent interruptions (to practice) as inquiries are dealt with from other health professionals and patients seeking one or the other of the nurses. One of the nurses absents herself from the clinic at the start, as her other role as the urology nurse specialist requires that she attend to urgent matters elsewhere. The extended roles all four nurses hold outside of chemotherapy practice interfere with the smooth running of the clinic this day. This is 
observed to be a normal occurrence within this practice setting and goes in line with the multiple roles rural nurses have. These diverse roles are an asset in this environment as the nurses change, fit and adjust to changing practice conditions. The newest team member is an experienced nurse with many years of practice, and she is also responsible for coordinating care in a number of outpatient clinics. Her input and advice is sought several times during the day and at times she appears flustered and frustrated at the ongoing interruptions to her supervision and training. The patients arrive throughout the day at set times with their support persons. The atmosphere in the clinic is happy as bonds are quickly re-established amidst comments about the weather and the patient's wellbeing. Treatment delays are experienced throughout the day due to dispensing issues, blood testing and waiting for patients to be cannulated by staff in the emergency department who support the clinic with their skills. These delays are accepted as integral and are known as part and parcel of the practice environment; most of these issues are considered unavoidable, not being within anyone's control. These setbacks at times are noted to be stressful for nursing staff; particularly when informed that another patient has arrived and is waiting for treatment. The stress is evident in the looks they give each other and the terse comments made in passing to each other. The patients do not appear to be adversely affected and are frequently heard to express their relief that treatment is going ahead and gratitude that this is taking place in their local area. Despite these setbacks there is a joyful atmosphere in the clinic. There is also a sense of satisfaction from nurses and patients alike once a treatment is completed safely.

Conversations in the clinic centre mainly on general issues such as the weather and then move to more specific topics such as patient wellbeing, symptom management and assessment, education, sexuality and chemotherapy experiences. These conversations take place between the nurses and patients and between the patients themselves. I frequently observed the nurses praising and acknowledging the journey of their patients between cycles and giving them advice and hugs.

One of the patients in the clinic has come from a distant area and on hearing that her blood results are satisfactory to proceed with treatment, grabs her nurse and together 
they do a celebratory dance. The clinic erupts in laughter and in support of this momentous event. A sense of support and camaraderie exists between patients and nurses. Humour is observed to play a huge role in this setting by relieving the stress and anxiety experienced by those receiving care and those delivering care. The patients who come to the clinic also use their time there to have the nurse listen to their problems and solve some of their issues. Being a small community where everyone knows everyone else, patients are observed to offer informal advice, support and education to each other and often sit together for longer times supporting each other after their treatments are completed. Representatives from the local Cancer Society drop in to see those patients from distant areas and to also offer support in the form of meal and petrol vouchers.

The oncology nurse does not give chemotherapy this day. Her role is mainly supervising and assisting the nurses, coordinating care and offsite appointments, plus fielding telephone calls. During the morning when there is a break, she sits down with one of the nurses and assists her with a case study she has requested assistance to complete. Informal education is an important feature of practice in relation to keeping the nurses skilled to give safe care and equipping the patients with information that will improve their outcomes. Nursing practice is observed to be safe despite situational influences. Care is taken throughout the chemotherapy checking and giving process. The nurses are acutely aware that safe practice hinges on their care and attention to the details of administration. They are observed double checking drugs, calculations, patient identities, using protective equipment and measures that ensure practice is safe.

The end of a clinic day is most always a time for reflection and a cup of tea. The oncology nurse sits down with the new trainee and time is spent reflecting on her day and experiences. The new trainee has dealt with three patients and many interruptions. She admits finding this frustrating and stressful particularly as she's trying to learn new skills. The highlight of her day was the measure of trust shown to her by her three patients. They felt safe enough with her as their nurse to disclose personal issues and concerns that were particularly meaningful to them. This newest member of staff, rich in nursing and life experiences, had managed to achieve a lot in terms of emotional support 
for the patients that day. This could be attributed to the fact that she is well known to the patients having lived and worked in this area for a long time. This incident highlighted to me the fact that the function of the clinic is not just about giving chemotherapy; it's also about meeting a range of patient needs and the life experiences a nurse brings to the practice environment is an essential part of the basket of skills we utilise to improve patient outcomes.

\section{Personal Reflections - Snippets from practice journal}

It was only through working and living in this rural area that I (more) fully developed an appreciation for the challenging healthcare environment in which rural nurses work. My first few weeks in the area were certainly a period of adjustment and adaptation for me and I learnt valuable lessons along the way. At the outset of my tenure I knew that I had a lot of knowledge and skills to be able to influence practice however as practice changed so too did my nursing experiences change me. At first I found it difficult to understand why many of my patients would approach the local Cancer Society for help with medical issues bypassing me as the oncology nurse. It worried me, until I learnt that this was a common behaviour of long time rural residents who feel more comfortable seeking help first from other locals before accessing help from an outsider. I realised that trying to fit a city model of practice into a rural setting wasn't going to work. I learnt that adaptation and flexibility were key to practice and that things are not always what they appeared to (me to) be at first impression. I clearly remember the first two chemotherapy clinics I attended: the patients didn't appear to arrive at a set time; and they stayed on for long periods of time encroaching on what I considered were other's treatment times. Remembering my past practice experiences I decided to improve the organisation of the clinic and drew up a list and calculated how much time each treatment would take and informed the patients when they should arrive. The patients complied by arriving on time, however they didn't leave when I expected them to. They stayed behind for cups of tea, chatted to their friends (other patients), asked us advice about their health issues and to coordinate offsite appointments. I would be asked several times to phone a general practice to negotiate a free prescription for medication that had run out, with financial hardship often being cited as a reason. My experience 
that day illuminated for me the hidden role of the clinic in this area. The role of the chemotherapy clinic is one of socialisation, support, healing, networking and assistance in mitigating the cancer care burden for these patients. I thought I was a 'change agent ' and I left that day being a `somewhat changed agent.' My experiences of practice within this setting have shown me that although there are many challenges to delivering care it is possible to deliver safe care and this hinges greatly on the commitment and responsibility the nurses hold towards their practice. Although they have no control over many situational influences, they revealed just exactly how they have control over their individual practice and can refine the care they deliver to each person they meet. I am used to working in large city hospital with a vast array of resources at hand however; when I first came to this area I saw the deficits within the service as barriers and obstacles to good patient and nursing outcomes. My engagement with colleagues in this setting has shown me that their viewpoint is somewhat different to mine, in that barriers to practice in many instances are seen as challenges to seek new ways to deliver care. The nurse in the chemotherapy clinic is recognised by patients as being the person who plays a vital role in the care coordination and delivery of the service that is their life line in this area.

\section{Conclusion}

Challenges within and surrounding the practice environment shape the nature of care delivery. Despite these influences safety is paramount to practice in this setting and is reflected in what the nurses do and in the organisation of the clinic. The environment supports ongoing education and skills acquisition for its nursing staff and supports therapeutic relationships between the patients and nurses and between the patients themselves. Appointments take longer than they would elsewhere because of the hidden role of this service. In this chapter I have provided a descriptive glimpse of practice through my eyes illuminating the nature of practice within the clinic. If I were to provide a descriptive summary of practice I would truly say that it is rich, varied, filled with drama and laughter and hugely supportive of patients and nurses alike. The reason being that change happens and if you live in an isolated area you learn to rely on your friends and neighbours, and supportive networks (in turn) take on a new meaning. The next 
chapter discusses the findings of the study interviews and builds on the evidence used to inform this case study. 


\section{CHAPTER SIX: Study Findings - The Fabric that is the Clinic}

"Fabric - woven cloth, a framework or structure" (Collins et al., 2006, p. 276)

\section{Introduction}

The purpose of this chapter is to present additional findings which bring through the detail to the case study in light of data collected and analysed from the nursing interviews. I used multiple methods to gather information to construct a picture of practice that is this case. The research also focused on the issues that the nurses identified as affecting their practice. I will describe the characteristic profiles of the nurses working in this setting and the nature of practice in relation to them as revealed through three major themes which were consistently identified from the gathered data. These themes are summarised in Table 2 below and will be the focus of this chapter, together with the strategies the nurses suggest to improve practice. Socio-economic, political, contextual and situational influences have all contributed to the shape and form of what is essentially the fabric of chemotherapy practice in this New Zealand setting. This descriptive case study reflects the viewpoints of participants involved in the case and hence the nature of practice needs to be interpreted in light of this fact. I have used exemplars and summarised statements of practice developed from the nursing interviews to illustrate some of the study findings.

Table 2: Major themes: Chemotherapy Practice in a Rural New Zealand Setting

1. The holes in the safety net - Barriers to practice

2. Cushioning the impact - The safety net

3. Evolving practice 


\section{Characteristic Profile of Nurses}

Four nurses, including the oncology nurse who was on extended leave and had returned to the area at the time of the study, agreed to participate in this research. Table 3 presents a profile of the nurses interviewed for the study.

\section{Table 3: Profile of Four Participants}

Demographic

Information

Details

Age

Sex

Years nursing

Long time rural dwellers

New comer to rural area
Range $40-50$ years

All female

Range 20 - 29 years

3 of the nurses

1 nurse

Three of the nurses have lived and worked in rural areas most of their lives and these same nurses have had no prior chemotherapy experience before involvement with this nurse-led service. One of the nurses is new to the area and has had some oncology and haematology nursing experiences and previous chemotherapy involvement. The nurses are experienced practitioners and all have over twenty years nursing experience. The age of the nurses' range between 40 to 50 years and all hold a variety of roles within this base hospital. For example, the palliative care nurse is also the urology specialist nurse and when the occasion demands takes on the oncology nurse role. Improving the quality of care for their patients, service gaps, past experiences and the need to acquire new skills and knowledge were the influencing factors behind these nurses becoming involved in chemotherapy practice. The following accounts illustrate these factors and show why these nurses responded by developing a nurse-led clinic:

I knew when I applied for the job it was part of the role...I thought well it's not going to happen unless I go and do the course and actually start doing it myself (Participant 4).

In the haematology clinic we had a little old lady sitting in a chair crying and crying...it was not the chemotherapy she was upset about; it was the big drive over, driving in the 
city, finding a car park, just everything in the city. So when we decided we were coming here... I thought well, I'll get involved in chemo. And maybe a few more people won't have to go over there (Participant 2).

I think its getting to know them and seeing their stories and their journey's, it's better being involved - I think it was just a development from all that, the next step was being able to be involved in their treatment (Participant 1).

\section{The Nature of Practice}

The nature of chemotherapy practice in a nurse led clinic is revealed in this chapter in a presentation of three major themes which emerged from the data (see Table 2). 'The holes in the safety net' identify the barriers to practice identified by the nurses in this rural setting. 'Cushioning the impact' highlights the strategies employed by these nurses to lessen the impact of contextual and situational influences on care. The third theme 'evolving practice' describes how these nurses viewed the impact of education, mentoring and support on their individual practice.

\section{The holes in the safety net - Barriers to practice}

'The hole in the safety net' is the title of the first major theme to emerge from the data which reveals the barriers to practice as identified by the nurses in this study. Some of the barriers described as contextual are; geographical location, isolation and distance and are part of the cost borne by people choosing to live and work in rural locations situated a distance away from mainstream treatment centres. The barriers to practice as identified in this study have been summarised in Table 4. Collectively the nurses described many services and organisational issues that impact on practice; secondly they described the issues they recognise directly affect the patient and lastly they describe the issues they view as impacting on their own practice. 
Table 4: The Holes in the Net: Barriers Impacting on Practice

\begin{tabular}{ll}
\hline Barriers & Description \\
\hline Service issues & No dedicated chemotherapy room, limited equipment \\
& Problems with the supply and delivery of drugs, and getting \\
& prescriptions on time \\
& Recruitment and retention of allied health staff who support \\
& clinic \\
& Little or no input from onsite doctors \\
& Knowledge gaps in medical staff regarding chemotherapy \\
& Poor communication between consultants \\
& Distance impacting on access and treatment decisions \\
& Lack of local after hours support for chemotherapy patients \\
& Difficult cannulations, need for patients to travel long distances \\
& to have central venous access devices inserted \\
& Patients may not see oncologist for at least 2 - 3 cycles of \\
treatment & Huge socio-economic burden of care \\
Direct patient issues & Variable standard of post chemotherapy care if admitted to local \\
hospital & Limited patient numbers for competency development \\
New practitioners supporting new practitioners, with no means \\
of comparing practice \\
Limited nurses available impacting on time off to attend \\
educational courses, and availability to give chemotherapy \\
No-one to replace staff when they are away \\
Being left alone to give chemotherapy \\
Knowledge gaps, lack of oncology educational support \\
Direct nursing issues
\end{tabular}




\section{Service Issues}

The lack of a dedicated chemotherapy room and adequate equipment resources to enhance practice was a strong issue that resonated throughout the data for these nurses. The frustrations of having to look for supplementary equipment on a weekly basis, such as pumps and intravenous stands (to facilitate treatment) and not having a regular room set up (for treatment) was seen by these nurses as significantly impacting on the smooth operation of the service. Patient care and nursing practice is disrupted and compromised. These accounts highlight the impact of these influences on practice:

Our physical environment is certainly far from ideal. We have to go and beg and borrow and steal equipment from all over the hospital. We're sort of doing chemotherapy on a bit of a shoestring budget really - we're like the Cinderella's of the service (Participant $3)$.

Having our own equipment and everything set up in the room just for chemotherapy would make things easier...People would know that was where they were going to have it (the chemotherapy) and that it is in that room and that the room wasn't going to get changed at the drop of a hat or at the last minute (Participant 1).

If there was a chemo spill, it wouldn't be very safe because we haven't got a proper room to handle that sort of thing; our facilities aren't as good as they could be (Participant 2).

Other departments in the hospital support the smooth operation of the chemotherapy clinic mainly the accident and emergency service, the laboratory and the pharmacy. The pharmacy plays a crucial role in the ordering, dispensing and supply of chemotherapy drugs and as a safety check in regard to dosages and patient blood results in order to proceed with treatment. The nurses have described how a failure within one service department has the impact to significantly affect the service they provide and patient care. An example of this is highlighted in this account by participant three: 
We've certainly had chemotherapy not turn up. We've had to turn patients away which has being hugely devastating for the patients who have travelled and psyched themselves up for chemotherapy and we turn around and say, 'Oh I'm sorry it hasn't turned up because the pharmacy hasn't ordered it or in actual fact (name withheld) hasn't sent it.'

For the nurses in this study recruitment and retention issues around skilled hospital pharmacists have been responsible for some of the service issues they've experienced in their department. As maintained by this nurse:

We've got a full time pharmacist now for the moment - I don't know how long that's going to last but hopefully it will and we haven't had too many problems with this one so far (Participant 1).

Because nursing and medical staff on the wards have knowledge gaps in relation to chemotherapy the nurses identified this as impacting on their own role in patient care. There is little or no input from onsite doctors into this nurse-led service. The significance of this has meant that the nurses play a crucial role in the event of emergencies encountered within the chemotherapy setting.

We've had little or no input from doctors as such even though we're based at the outpatient department. If anything immediately goes wrong, I think that we're still the pivotal people that are going to deal with that emergency situation (Participant 3 ).

Many staff working in this area have little or no experience with chemotherapy practice.

I think the doctors don't feel confident with chemotherapy (we certainly saw that a lot last year) just as most nurses working on that ward have never come across chemo or have given it (Participant 3). 
The nurses in this study maintain that communication between the main oncology centre and doctors in this area is poor and could be improved to enhance practice and patient outcomes. As this nurse reflects:

It's difficult when the main physician is in (place name withheld) and perhaps the physician here feels one step down. We've found them reluctant to liaise with the physicians over there (Participant 3 ).

The potential for these service issues to impact significantly on the quality of service for patients in the clinic and nursing outcomes have been identified by the nurses in this study. The next section focuses on the barriers to patient care as described by the nurses.

\section{Direct Patient Issues}

The nurses collectively described how the impact of distance on access to care, treatment decisions, timely blood results and diagnostic facilities impact on patient care. Some patients live many hours away from medical help or in areas with no doctors. If the weather is poor then these patients can't access care when required. The decision to have treatment for those living in isolated areas is not taken lightly. As related by this nurse:

They live in areas where they may be up to two hours away from getting any medical assistance. There may not be a doctor in their area at all, and if the weather is bad they can't get to us anyway (Participant 1).

After hours access and support for chemotherapy patients is limited and fractured and is perceived by the nurses to be a weak link in the service.

There's no after hours service as such and it feels as if patients are left in limbo. Their only back up is the A and E department at the base hospital. The services at (name withheld) are very basic. The support at the end of the phone is missing (Participant 3). 
When planning care the nurses take into consideration all these factors noting them to be crucial to successful outcomes and patient's coping abilities. Where a patient lives has implications for when treatment is delivered and their post chemotherapy care.

Getting patients down is an issue - relatives can get sick. You can't give chemotherapy and let them go away unless they were staying here. Its three to four hours away. There's no proper medical backup and what if they pass out from a delayed reaction. If someone wanted chemotherapy, and was living far away, they would need to be committed to staying here for a few days (Participant 1).

The nurses in this study also acknowledge that many of the barriers to practice as experienced by the patients are out of their control.

I don't know how we can improve the fact that there are a lot of people from good distances that have to travel, and getting bloods done isn't an easy thing. Patients actually forget believe it (or not) to have their bloods taken (Participant 3).

The barriers to optimal patient care in this area are influenced by contextual challenges, which encompass the distance patients live away from the treatment centre, the weather, access to resources and after hours support. The nurses in this study are cognisant of these factors when planning care. The next section reveals the issues the nurses saw as impacting on their practice.

\section{Issues Directly Impacting on Nursing Practice}

The nurses have described the challenges within practice around maintaining their skills and competency. These include the other roles they hold, limited patient numbers for practice development, infrequency of chemotherapy practice and getting time off to attend educational courses. The clinics are held weekly on a Thursday and some nurses may only get to give chemotherapy once or twice a month. 
As nurses we do not have huge chemo patient loads, the risks are that we may not be as skilled on a day to day basis as our colleagues in the city who are giving chemo more frequently (Participant 4).

Education is recognised as a key component of safe practice for these nurses. These nurses collectively identified barriers to attending educational courses particularly when these are held off site. These barriers include workloads, their other roles, limited staffing resources and no-one to do their job if they are away. As related by this nurse:

I missed out on the biohazard study part of it. I couldn't get back to do that, so that's one of the problems that I have, being free from my other roles to participate in that role...It's quite difficult for me (Participant 1).

These nurses also identified individual knowledge gaps in relation to enhancing their practice and feeling safe. Competency in administering chemotherapy with no subsequent attention to their theoretical knowledge is acknowledged by these nurses as having implications for their safe practice and patient outcomes and was an issue of concern for them. These nurses work in isolation from mainstream oncology treatment centres with no oncology peer review and ongoing oncology in-service education. As this nurse puts it:

If we don't have education, there's a real risk with safety. My knowledge in oncology is not great (Participant 2).

It's quite hard coming in and giving chemo without the knowledge behind it (Participant 1).

These sentiments were particularly relevant to the nurses who had only been working in the clinic for a short period of time and are indicative of their feelings behind not having the theoretical education to build up their skills and knowledge in this area. The nurses working in this nurse-led service see themselves as new practitioners who are in turn 
supporting new practitioners and this has implications for the direction and shape of the service and their practice. Specialised help is most often accessible by telephone, however offsite oncology services are three and a half hours away and they lack the benefit of seeing how other practice settings function.

I don't know how chemotherapy clinics' function. I don't know if they have a resident doctor you see at the door or if it's all run by nurses. I haven't seen any other clinics to compare with how ours is run (Participant 1 ).

Dependant on patient numbers, at times the oncology nurse or the palliative care nurse may be the sole practitioner delivering treatment. Nurses are often left alone for brief periods of time when giving chemotherapy because the second nurse may be engaged in other tasks or called to attend an emergency. This has implications for safe practice given the unpredictable nature of chemotherapy practice and can be a terrifying experience for the nurse left alone who has to deal with an unexpected emergency situation. The following descriptive account by participant three illustrates this issue:

We were giving this gentleman his R-CHOP. The other nurse had to pop out for only ten minutes. This gentleman needed to go to the toilet, which was virtually five minutes across the hall. By the time this gentleman had got back to the room he was having what we thought was an allergic reaction to the Rituximab and had bottomed out on his blood pressure. He was getting grey, his blood pressure un-recordable and he collapsed into my arms, where I managed to get him to the Lazy boy chair. There was no bell - the other nurse was called away for five minutes, so that was an extremely terrifying experience for me, I must admit.

You can't predict what's going to happen and at the worst possible time, when someone's out of the room (Participant 3) 
Despite the obstacles encountered in their practice the nurses in this study did not view practice as unsafe and when asked to describe this nurse-led service the nurses maintained that the clinic is well run and safe.

I think we do most things well - I think we relate well to people - I think we safely give chemotherapy (Participant 1).

Frequent interruptions to practice are commonplace in this setting as patients or other health professionals seek one or another of the nurses. This appears to be characteristic of rural practice and goes in line with limited staffing resources necessitating nurses with multiple skills in varied roles to better meet their patient's needs. This was confirmed in this description of practice by this nurse:

There's so many roles that each person hold, they've often got other things to do, emergencies that they've got to go out and handle (Participant 2).

Four nurses are involved in chemotherapy practice and their availability is not always guaranteed. The oncology and palliative care nurse play a crucial role in the clinic and if one or both of these nurses are away for whatever reason this has an impact on the service as there is no one else to pick up their role. They have identified a need for the other nurses to know their roles in order to maintain the service. The reflections by this nurse highlight the impact of staffing resources and role diffusion on the maintenance of this service:

We're talking about limited resources. I mean we really only have four nurses that give chemotherapy and unless you take into account the fact that you know those nurses have other jobs. So if a nurse leaves, there's sick leave, we run on a bit of a shoe string really with staffing resources... If we are away for whatever reason, all falls down... because we are small and there's not many of us (Participant 3). 
The nurses in this study have described many barriers and influences affecting their ongoing professional development due to the varied roles they hold, staffing resources and limited patient numbers in the clinic for practice development. The next section deals with the challenges of maintaining safe care in this setting and the strategies the nurses use to cushion the impact of contextual and situational influences on practice.

\section{Cushioning the Impact - the Safety Net}

'Cushioning the impact - the safety net' is the title of the second predominant theme to emerge from the data which focuses on the processes and activities the nurses engage in to cushion their patients and themselves from the impact of situational influences. This study has revealed the many challenges the nurses face when seeking to deliver care and the challenges patients face when accessing that care. This study confirms that the function of the clinic varies according to the patient situation and that there is a lot of role diffusion amongst nursing staff. The nurse giving the patient their treatment today could well be the same nurse coordinating care in another clinic and is thus in a position to expedite speedy access to ongoing care if required. This study showed that the staff working in the clinic are an integral link between the different services when it comes to coordinating and advocating for good patient care. The clinic is not simply just about giving chemotherapy; it's about meeting a range of patient and nursing needs. Appointments are arranged so that support can be offered from those in similar circumstances and also in consideration of the distances patients have to travel to the clinic. Patients ask the nurses advice on a range of medical and social issues and seek assistance with various problems they are encountering. The study found that the nurses collectively contrived to create a safe therapeutic environment to support, provide reassurance, consistency and holistic care to their patients and family members. They are most often involved in their patients care from the beginning to the end of the illness trajectory. When describing practice within the clinic this is what this nurse relates:

In the clinic we have lots of laughter and fun. We treat the whole person. Appointments are longer, it's a friendly small intimate environment. ... We help them on their journey 
of cancer, support them, and travel beside them with our care and knowledge (Participant 1).

The knowledge that these local nurses have of their patients and their families through living and working in this area is seen as having a positive influence on patient care in terms of the support offered, continuity of care and help in navigating the health care system. The nature of the nursing involvement in patient care is encapsulated in this statement:

We are right there through the whole journey for these people. We become very close to them and their families, so there's a lot of positive therapeutic relationships (Participant $3)$.

The provision of treatment in their local area has benefited many cancer patients by reducing the socio-economic and social impact of the illness. As this nurse maintains:

It's such a vital thing for people to be able to have their chemotherapy on the (name withheld). I mean travel is hugely onerous on patients, having to travel on a three weekly basis to (name withheld). It has a huge impact on their ability to cope (Participant 3).

The nurses in this study view education as a strategy to strengthen their own personal practice and as a means of equipping patients with information to keep them safe so that they will know what to do if they become unwell.

The education is just so important, that they will be safe, that they'll ring us up if they have a problem (Participant 2 ).

In turn patients are also taught to be assertive when it comes to advocating for their care, given the practice environment and the fact that many medical professionals have 
knowledge gaps in relation to chemotherapy practice and related side effects. As this nurse stated:

It's also about teaching our patients to be assertive enough to say that what I need is to have my blood tested and not get fobbed off (Participant 4).

The nurses collectively view the culture of the clinic as supportive not only of patients but of themselves and their practice. Recognising knowledge gaps and the barriers to obtaining education specific to their situation, the nurses in this study embarked on regular monthly educational sessions held in the clinic to improve their skills and confidence. A description of this type of support is put forward by this nurse:

We have an education day once a month that affects our nursing care a lot you know, it just grows and it make us feel more confident with what we're doing. ... The chemo clinic is a supportive environment for staff within the unit (Participant 2).

In terms of the rural location and staffing resources the nurses described their roles and relationships with other services, each other and their responsibility for practice, as vital to good patient and nursing outcomes.

We're a small team and you can't afford to let things simmer, we work well together (Participant 3).

The nurses access advice and support from off-site oncology services, although at times this may not be readily available or easily accessible. The nurses have become an integral part of their patients care and in particular the oncology and palliative care nurses carry an immense responsibility for these patients which does not stop when treatment is over. These nursing responsibilities spill over into times when these nurses are off duty and the measure of their commitment to patient care is seen by their willingness to see these patients out of duty hours. 
Our responsibilities don't just stop when they walk out the clinic; those responsibilities go to those people who are out there in the community (Participant 3).

Well our patients sit in $A \& E$ for quite a long time waiting to be seen. They are supposed to be triaged one. If I'm around I'll come in and deal with them (Participant 4).

Having chemotherapy treatment in a rural situation challenged by many practice issues, has seen a number of strategies and processes employed to cushion the impact of these influences. The way the nurses deliver care, look after and educate their patients, take measures to address competency issues and foster supportive relationships are key findings of this part of the study. Evolving practice is the focus of the next section of this chapter and reveals the influences of education, mentoring and support on the practice of these nurses.

\section{Evolving Practice}

The third predominant theme in this study is entitled 'evolving practice' and reveals the changing nature of the practice of these nurses in relation to education, support and mentoring by the oncology nurse specialist. Nursing practice changes and evolves according to internal and external influences. The researcher coming into this practice setting as the oncology nurse specialist, with a number of years experience in acute and palliative care oncology had an influence on practice directly and indirectly. The study reveals how the three nurses working with the researcher acknowledge the evolution and growth of their practice in relation to walking alongside an experienced mentor, and ongoing education. The following statements by this nurse encapsulate the evolution of practice within the clinic.

We have informal education throughout our clinic hours with different members being able to share different areas of knowledge as topics come up. ... With education sessions once a month we are extending our knowledge base which impacts significantly on our confidence and care of patients. ... We help each other to reach their full potential 
within our nurse-led clinic. We have a coordinator to lead us and are all encouraged to fully achieve within our clinic (Participant 2).

Two of the nurses in this study were engaged in professional educational courses at the time of the research. The monthly sessions in the clinic were tailored specifically to issues related to oncology and chemotherapy practice and, coupled with a supportive training environment, were found to have significantly contributed to the nurses knowledge, confidence, skills and growth in practice. As this nurse reflects:

I think that we have had huge improvements in our chemotherapy and in the way that we do it this year. It's absolutely not perfect but I think that new blood, a new broom coming and looking at it in a different way has made our service a better service. I think it's made us more confident, it's made us look at our education and the fact that we need to keep ourselves up to date...Next year we'll have had someone else (return) that's gone away and given chemotherapy in another country. I think that she'll be bringing new fresh ideas about how we can improve it (Participant 3).

The implications of 'on the job training' education and mentoring have significance particularly when applied to rural situations where nurses experience a number of challenges trying to improve their practice in specific specialities. Increased knowledge, improved confidence and skills were the benefits accrued by these nurses, who saw their practice evolve as a result of walking alongside an experienced oncology nurse. The following section of this chapter deals with the strategies the nurses identified that could be employed to enhance and improve practice.

\section{Strengthening Practice}

When asked about how their practice could be improved in this clinical setting, the nurses in this study identified a number of strategies that could be used to improve practice (see Table 5). 
Table 5: Strategies to Strengthen Practice

\section{Description}

A dedicated adequately resourced chemotherapy room

Time away to improve skills and gain experience at main oncology centre

Regular ongoing specific education to address knowledge gaps

More educational support and input from the main oncology centre

Improvement of quality systems within other departments that support the clinic

Better communication between the oncology centre and clinic regarding changes to

protocols and guidelines

Organised tele-med links with oncologists for those patients who will not be seen for

lengthy periods

Organised meetings with other rural chemotherapy practitioners to exchange ideas and

enhance practice

Training of other nurses involved in the clinic regarding the organizational and technical aspects of practice as the oncology nurse is not always available

Managerial support and financial input

Improved medical backup and knowledge to handle chemotherapy- related issues

One strategy involved time off from their other roles to work in the main oncology centre to maintain their skills, coupled with educational support specific to their practice area locally and off site. There was also the need for better communication between the oncology centre and this clinic, particularly in relation to changes in any drug protocols and guidelines, so that practice is consistent. Telemedicine was suggested as a way of linking up with oncologists to provide support for some patients who may not be seen for two or more cycles. Meeting with other rural nurses involved in chemotherapy practice was a wish expressed by the oncology nurse as a way of exchanging ideas and enhancing practice. The provision of an adequately resourced dedicated chemotherapy room was a strong issue for all these nurses as well as improving the systems within the 
departments that support the clinic, so that patient service is not compromised. Linked to service growth and support was ongoing managerial and financial support. This point was put across succinctly by this nurse who maintains that:

I certainly cannot see it growing if it is not adequately supported by our managers and it won't grow if money is not put into it... and if we don't allow our staff to have the education that they need (Participant 3).

An issue to arise from this study was that some nurses found it difficult to articulate a vision for the service given their limited practice experience. As reflected by this nurse:

Personally I don't think that I've had enough experience in chemotherapy and being part time, it's actually quite difficult for me to have a vision of how to improve the service...I'm probably having to and have been relying on other peoples experiences and vision to improve my weaknesses and to improve the service (Participant 3 ).

\section{Conclusion}

In concluding this chapter, it could be said that the nature of practice within this rural setting is challenging with many situational and contextual influences impacting on practice. The nurses deliver care in a less than ideal environment, with limited resources, and face many challenges to maintain their skills and competency. Despite these obstacles practice within the clinic is viewed as safe. Education is essential to keep nurses and patients safe. The nurses suggested many strategies to improve and enhance practice amongst these a dedicated adequately resourced chemotherapy room to provide optimum patient and nursing care. The practice of the nurses continues to evolve in response to influences in and around practice. The fabric that is essentially the clinic is rich, varied and continually changing. In Chapter Seven I discuss the significance of the findings of this study together with the implications for practice. I also discuss the findings in light of the two theoretical propositions that were developed prior to entering into the research. 


\section{CHAPTER SEVEN: DISCUSSION OF RESULTS - MAINTAINING THE FABRIC}

"To maintain - to care for, keep up or preserve an activity" (Collins et al., 2006, p. 463).

\section{Overview of study}

The purpose of this chapter is to discuss the findings of this study and to reveal new insights into this research with reference to supporting literature to verify or challenge the results. In this chapter I also discuss the findings in light of the two theoretical propositions that were developed prior to conducting the research. The study limitations impact on the discussion. These included a small sample size and the fact that the research took place within a time frame under the influence of a new oncology nurse specialist. There are many service providers directly or indirectly involved with this clinic and it would have been useful to gain their perspective on practice issues. In light of these points and in order to scale this project only the nurses involved with the chemotherapy clinic were included in this research. The results of this study need to be interpreted in light of these boundaries. Initially I did see them as limitations, but as I worked with the data from the project I realised that the intent of this case study was not to generalise findings to other rural settings. Readers may of course identify commonalities with the nature of chemotherapy practice, no matter the setting, but I have chosen to present this without comparison being made beyond the context and beyond my own experience as a cancer nurse. Given this positioning, this study does provide an account of actual chemotherapy practice in a nurse-led service in a rural New Zealand setting and is likely to have important implications for practice development.

The case study is presented to build on knowledge in this subject area and to hopefully provide a forum to debate issues affecting service delivery with the aim to advocate for best practice. This case study is also important in view of the socio-political implications of market forces on our healthcare environment. The ever shrinking healthcare dollar is 
set against an environment where, people are living longer with chronic disease, sicker patients are seen in the outpatient setting, and there is a global shortage of nurses; and that is not expected to improve in the near future (Block, Claffey, Korow \& McCaffrey, 2005). All these things impact on the shape and direction of our services and the ability of healthcare providers to provide a sustainable healthcare system.

The following discussion is presented as a whole case study to reveal the nature of practice. When I reflect on the word 'nature' to me it encapsulates the following; the challenges of working in this area; the context; the isolation; the characteristics of the people; the geography and climate; the significance of working with cytotoxics; patient safety and practice development. Although this case is made up of many parts the case is made most explicit through the nurses' statements and my engagement with them. I then locate these insights in literature that builds a picture to convey to readers the realities of what it's like to be in this practice setting. This case study also establishes how a rural service manages to deliver a highly specialised nursing service requiring advanced nursing practice to the people of this region.

Two theoretical propositions bounded this case and framed the way the detail was arranged in the discussion. These hypothetical statements meant that I was standing in different positions to see the three dimensional but I was also aware of the whole in response to these two concerns. I restate them again and, then after the discussion indicate how they impacted on how I have shaped the interaction in the project and (of course) the discussion. The first proposition sought to examine how the survival and support of chemotherapy practice in rural areas was grounded in mutually beneficial relationships fostered by contextual influences in and around practice. The second proposition sought to test my assumption that if attention was paid to developing a nurse's knowledge and skills, whilst providing her with appropriate resources, these would provide the patient with greater protection and improve chemotherapy treatment outcomes. This study has provided a descriptive case study of chemotherapy practice. It has also uncovered the issues the nurses identified as affecting their practice together with their suggestions for improved practice. Maintaining and strengthening the fabric of 
this service is important to cancer care outcomes of patients in this region and has wider workforce implications.

\section{Discussion and Implications for practice}

It's presumptuous to assume that any healthcare service stands alone. The connections, threads and relationships that form the integrated parts of our health service are crucial to the sustainability and quality of the service provided. The conceptual framework underpinning this case allowed investigation into the composite parts of this system within its context. Three themes were extracted from the data gathered to inform the research, and were a result of my interpretation of the information. These themes encapsulate the nature of practice as it pertains to this setting as revealed by the nurses and they will be discussed in relation to the literature. The first theme to emerge, 'the holes in the safety net' signify the barriers the nurses identified as affecting practice. The barriers to practice could be summarised as those directly impacting on the service and organisation; those directly impacting on the patient; and lastly those barriers that impact on the nurses' own practice.

\section{The holes in the safety net - Barriers to practice}

This case study has shown that resource issues, system failures and problems in other departments in the hospital setting, have the potential to significantly impact on the functioning of this service. The success and support of this clinic is dependant on strong multidisciplinary links with many services. Included in these essential links are the accident and emergency department, the pharmacy, the laboratory, the hospital wards, offsite oncology services and the local Cancer Society. Some of the issues identified by the nurses as impacting on patient and nursing care included the lack of a regular designated treatment room, insufficient equipment and problems with the ordering, timely arrival and dispensing of chemotherapy drugs. The pharmacy department plays a crucial role in supporting this service and had experienced significant problems the year of the study due to personnel difficulties to attract and retain skilled pharmacists. The flow-on effect (of this) has meant that patients have experienced delays in their treatments, nursing schedules have had to be adjusted, and overall care is placed under 
threat. These problems are not uncommon to rural healthcare providers whose resource constraints and staffing issues impact on their ability to deliver an optimum service. These findings which show problems with a lack of service integration impacting on care in other departments are consistent with wider research literature on this subject (Curtiss, 1993; Dewar, Steginga, Dunn, McCarthy, Yates, et al., 2003; Ross, 1999; Turnbull, 2001). To a lesser degree urban settings do experience similar issues which are recognised by Lamkin, Rosiak, Buerhaus, Mallory and Williams (2001). The alignment of the different parts of healthcare systems in relation to quality indicators, cost efficiency and a seamless transition to care for patients is a contemporary topic that is receiving increasing attention in the healthcare literature (Gilchrist, 2006, Montagu, 2006, Turnbull, 2001). This is because of increasing evidence that failures in one area can significantly impact on care in another and also because of the fiscal constraints imposed on health providers who must prove cost efficient quality services in a climate of accountability for actions. Cluttered workplace environments, stress, fatigue and uncontrolled practice variables all increase the potential for chemotherapy errors to occur (Gilbar, 2001; Schulmeister, 2005). Observations of the practice environment showed that chemotherapy is delivered under less than ideal conditions and that the nurses' practice is beset by frequent distractions. These distractions in the form of frequent interruptions to practice occur mainly as a result of the other roles the nurses have. Although they appeared to find these stressful, particularly at busy times, it was not a significant issue for them. Recent literature to emerge has linked the nursing work environment and job stressors to job satisfaction, quality of care, safety and retention issues (Egglefield-Beaudoin \& Edgar, 2003; Lin \& Liang, 2007; Schulmeister, 2005).

The nurses themselves in this study indicated how service gaps have put patients and nurses at risk. There is limited after hours support for patients receiving chemotherapy. Oncology specialist care and input is not always easily accessible or timely. There is little or no input from onsite doctors into this nurse-led service and for many health professionals working in this area they recognise that they have significant knowledge gaps in relation to oncology and chemotherapy practice. Nurses at times have to give chemotherapy alone as the sole practitioner. Poor communication between consultants 
and offsite oncology services was identified as an additional issue affecting outcomes in this service. The literature cites similar circumstances in rural Australia (McCarthy \& Hegney, 2001; McCarthy et al., 2003; Yates et al., 2000). However the hospital is not operating in crisis mode according to the nurses and they were able to reveal how they took charge of their practice as professionals. This service needs to be evaluated to assess if it's meeting its objectives and to identify care gaps with the ultimate aim of improved services. There is a need in this area to address resource issues within the clinic and look into improved integration within the different departments because of wider implications for patient, nursing and service outcomes. Egglefield-Beaudoin and Edgar (2003) purport that "Until we know exactly what composes nurse's work and affects their work lives, we will not be able to enhance its quality.” (p. 106)

The evaluation of services is also linked to the strategic objectives in the Government Cancer Control Strategic Action Plan (2005) and in its attempts to improve cancer care outcomes. The financial implications of failures to meet treatment schedules because of system failures and poor coordination is huge and often affects the patient directly (Bourke et al., 2004; Turnbull, 2001). The drama played out in this practice setting reveals costs associated with long distance travel, childcare, patient distress and the loss of income for working support persons of patients receiving treatment. There are the additional costs of adjusting treatment schedules and nursing time as the service adjusts to these influences.

Typically in health services in large city based centres management input is required to look at how service gaps may be addressed. In small settings the practitioners themselves have established the service and are aware they need to audit and evolve the services. Furthermore, a needs analysis and evaluation of this service was recognised as being required to strengthen existing practice. My role as peer in this setting was to articulate the nature of advanced chemotherapy nurse practice within the cancer nursing role. Such practice analysis identifies care gaps which are argued as being essential to the evolution of best practice and therefore essential to the ongoing provision and maintenance of a safe, quality service (Gilchrist, 2006; Montagu, 2006). 


\section{Cushioning the impact - the safety net}

The second theme extracted from the data was entitled 'Cushioning the impact - the safety net' and reveals the strategies these nurses have employed in their practice to lessen the impact of contextual and situational influences on care. It was evident in all nursing interviews that the nurses in this study have multiple nursing roles and function in a variety of capacities necessary to meet the needs of their patients and the service they work in. Quite often in the chemotherapy clinic the nurses find themselves dealing with a wide array of medical and social conditions. Having a good general knowledge of many patient conditions, varied clinical experiences and the flexibility to move within different roles is seen by these nurses as crucial to good outcomes. The patients who come to the clinic use their time there not only to have chemotherapy but to have the nurse listen to their problems, solve symptom issues and to share their concerns and experiences. When describing the nature of practice in the clinic the nurses used terms such as supportive, therapeutic, intimate, friendly, and humorous with a family atmosphere. The study found that these nurses had created a supportive environment for themselves and the patients and the clinic revealed its hidden role. This could be reflective of rural situations which in turn have necessitated supportive relationships amongst people to see them through difficult times (Bushy, 2000). When I first started working in this area I made comparisons based on my past experiences in a city hospital and I saw many of the deficits in practice and resource issues as huge barriers to patient outcomes and practice. This was my view and certainly that of the nurse who was a newcomer to this area. However we both learnt that our viewpoints were diametrically opposed to those of the nurses who were long time residents in this area. What I viewed as barriers were seen by these nurses as opportunities to develop new ways of caring for the patients and supporting nursing practice. The multiple roles and the continual acquisition of new skills by these nurses, and the creation of a therapeutic environment within the clinic to improve the care they provide, support this view. There is the additional fact that most of these nurses know their patients well and that comes from living and working in a small community. The nurses provide continuity of care and support, and adaptation and flexibility appear to be key characteristics of this nurse practice. Literature into rural nursing suggests that this could partly be due to the learnt 
ability rural nurses have developed which enables them to work best with what they've got under difficult circumstances (Bushy, 2006; Long, Scharff \& Weinert, 1997; Ross, 1999). This ability could also be viewed as an asset in areas functioning with limited resources.

Providing a safety net for patients has not come without cost to these nurses. The nurses in this study recognise that cancer patient care encompasses multiple roles. However this has major implications for their responsibilities, particularly when working in an area hampered by staffing constraints and distance from specialist support services. In this study nursing roles and responsibilities were revealed to be heightened in relation to service gaps. The nurses describe their burden of responsibility as huge however they did view themselves as principal holders of knowledge in this area of practice. Particularly for the oncology and palliative care nurses, their involvement in patient care begins from the diagnosis to the end of the cancer trajectory. This burden of responsibility has extended to the point where these nurses have at times made themselves available to patients for care after hours and on weekends. These service gaps have created an unequal load of responsibility and pressure upon these nurses. The nurses' value and enjoy a large degree of professional autonomy and recognise their professional responsibility as they practice in relative isolation from oncology support. This has implications for their practice accountability, job satisfaction and also raises the issue of support for them. The current focus on cancer care outcomes is on reducing the 'cancer burden of care' (Ministry of Health, 2003a). I suggest that we need to also look into the burden of responsibility that rural oncology and palliative care nurses experience as they work as sole practitioners in their speciality areas. Studies have confirmed that nurses are working harder, have heavier patient workloads and that the profession has become physically and mentally challenging (Beatty, 2001; Bourke et al., 2004; Day, Minichiello \& Madison, 2006; Joiner \& Bartram, 2004). The reasons for this have being linked to the current health work force shortages, fiscal constraints and increased service and patient demands. Some nurses working in rural areas may be the sole health provider, and thus they provide an array of patient services, some of these maybe outside the scope of their practice (Beatty, 2001). The current burden of 
responsibility the nurses in this nurse-led service face has implications for this service, particularly in view of the anticipated growth in the numbers of people expected to develop cancer. This means that future workforce requirements and problems around the recruitment and retention of skilled staff will impact on care delivery in this area. The significance of this burden of responsibility is highlighted particularly in view of the implications surrounding continuity of care when the oncology or palliative care nurse is away; services come to a standstill. Cancer is currently the leading cause of death in our society and 17000 patients are diagnosed with cancer every year in New Zealand and numbers are expected to increase (Ministry of Health, 2005). There are many times that the practice of rural nurses is compromised as they continually strive to meet the increasing demands of patients and the service in which they work (Curtiss, 1993; Ross, 1999). In addition general practitioner shortages in this area have further added to the pressures facing nurses (Ross). The pressures include; sustaining the ability to do a good job, monitoring for professional burnout and reviewing their decision as to whether they will remain in their areas of practice (these then become real issues). In addition there appeared to be some underlying tension between medical staff and nurses in this service that I discerned, as was suggested by some of the nurses' in their statements. They recognised that the doctors, despite their limited involvement in the clinic are still crucial in the event of an emergency, but are reliant on the nurses' knowledge in administering chemotherapy.

The conditions under which chemotherapy treatment is delivered can contribute to a high probability of errors (Gilbar, 2001). However a key finding of this study was that despite situational circumstances the nurses perceived their nursing practice to be safe. These findings challenge previously held assumptions that to deliver chemotherapy successfully a nurse needs to be operating from a foundation of oncology nursing knowledge (Buchsel \& Glennon, 2005). The ideal situation where a new service is set up is to have an experienced speciality nurse to coordinate and execute the service. These nurses have stated that they are essentially new practitioners supporting new practitioners. The reality of this clinic was made possible through a decision by a nurse to 'take the bull by the horns' and (get on and) do it. She maintains, that if she didn't 
make a stand and if the service had waited for this 'ideal' person to come along then it would not have been developed. In seeking to find an answer to why these nurses perceived their practice to be safe I consulted with the wider literature to explain this phenomenon.

Arbon (2004) talks about the holism of an individual nurse's practice which in essence allows her to be a therapeutic tool. This holism is built up from life and nursing experiences and not just from clinical experiences alone. The more holistic experience a nurse has, the more she is comfortable with her work. In terms of an experienced nurse entering a new area of speciality, he or she may first be concerned with core clinical care giving experiences associated with safety, and the use of equipment. In this nurse-led clinic it would mean that the nurse's focus would be on learning how to administer chemotherapy safely and learning how to utilise, for example, central venous access devices. He then maintains that as the nurse becomes more familiar with these aspects of care she becomes more comfortable and confident with her skills and in turn, her ability to provide safe care. He argues that too much focus in the past has been made of the skilled elements of care that has not recognised the other aspects of experience that contribute to holistic nursing. The nurses in this study are experienced nurses with many years of practice and Arbon's theory could explain why these nurses maintained their care was safe; they felt comfortable with their work. Their practice was safe because of other factors besides proficiency in performing the task of chemotherapy administration. These nurses came with a basketful of skills that incorporated life long learning, active listening and assessment skills and nursing experiences. The clinical aspects of practice were just a small but essential part of the bag of experience they brought to this setting.

Similarly, a study by Meretoja, Eriksson and Leino-Kilpi (2002) to identify indicators for competent safe nursing practice, suggested that competent practice was grounded in the holistic management and understanding of a clinical situation. In the performance of patient care, experienced nurses utilise many generic indicators of competent practice. Some of these include judgement, collaboration, teaching, situation appraisal and coaching skills. These indicators contribute to holistic practice and these tie into Arbon's 
(2004) theory of the holism of practice to ensure safe care. In endeavouring to explain this phenomenon my intent was not to delve into issues of competency, however the multifaceted nature of competence which the nurse brings to the treatment environment provides her with the confidence to provide safe care.

The nurses in this study viewed their practice as safe and were confident despite lacking a broader knowledge in oncology and chemotherapy practice issues. I argue that perhaps theses nurses had enough knowledge to be safe and competent without the depth of knowledge required to be considered as expert. Evans and Donnelly (2006) suggest that a skill is grounded in the context of the situation in which it is performed. They attempt to explain the relationship between knowledge, judgement and skills in practice and the links to confidence in a nurse's ability in the practice environment. They make reference to a personal communication with Benner in their study that provides an explanation around the dynamics of experienced nurses learning new skills. The proficient or expert nurse who chooses to gain new competencies in another clinical area is in essence a novice in that area. However because of their past experiences and deeper understanding of clinical practice and the body of nursing knowledge they bring with them, they move onto higher levels of proficiency faster that a student just out of nursing college. Linking Benner's explanation with that of Arbon's theory (2004) this means that these experienced nurses working in the chemotherapy clinic have reached a level of comfort and proficiency with their work hence they do not feel unsafe. Arbon's theory still remains to be tested; however it does provide an alternate explanation into why these nurses felt the way they did. In no way am I trying to diminish the importance of practice linked to experience in the work environment. However, I believe these nurses have proven that safe speciality care can be provided in rural areas as long as it is grounded in a personal commitment to safe practice, supported by professional relationships within and around the service and informed by extensive nursing experience. This finding has implications for the direction and development of services in New Zealand, particularly in rural areas. It implies that experienced nurses can obtain new core clinical competencies to set up new services and these will be safe. I suggest that the concept of 'the need will drive the wheels' will shape and develop future 
services. Curtiss (1993) suggests that when nurses are equipped with the skills and knowledge to maintain current practice, complex oncology care is possible in rural environments and this confirms the findings of this study. In turn Bushy (2000) contends that despite barriers to optimal practice, rural nurses are usually committed to maintaining current up to date practice, and are dedicated health professionals.

\section{Evolving practice}

The third theme extracted from the study data was entitled 'evolving practice' and reveals the changing nature of the practice of these nurses in relation to education, support and mentoring by the oncology nurse specialist. The influence of the oncology nurse specialist was acknowledged as the impetus for moving practice to another level. The result was increased knowledge, confidence and skills as she was able to support and provide further training for these nurses based on her wider experiences. Monthly education sessions were tailored to improve their knowledge with on-the-job support and training. Nursing has a long history of mentoring relationships both at a formal and informal level (Johnson, Cohen \& Hull, 1994). This statement by this nurse sum up the impact of the mentorship relationship on the practice environment:

I think that we have had huge improvements in our chemotherapy and the way that we do it this year. It's not absolutely perfect but I think that new blood; a new broom coming and looking at it in a different way has made our service a better service. I think it's made us more confident, it's made us look at our education and the fact that we need to keep ourselves up to date (Participant 3 ).

The implications of on the job training, education and mentorship have significance particularly when applied to rural situations and the literature increasingly links these factors to job satisfaction, workforce development, and recruitment and retention issues. Block et al. (2005) provide an overview of recent literature into the value of mentoring for healthcare organisations. They suggest that evidence exists to conclude that mentorship programmes do assist with retention issues and this is a cost effective strategy particularly when faced with retaining staff in a climate already affected with 
nursing shortages. The current nursing shortage is not expected to improve in the short term and some of the reasons given for this were job dissatisfaction, poor remuneration in comparison with other countries, workloads, burnout and nurses moving into other non clinical nursing roles (Block et al., 2005). Part of the solution advocated by Block et al. is for organisations to create supportive nursing environments where the nurses will want to work in, because they know they will be supported in their ongoing training and education. Similarly the findings of a study by Kilcullen (2007) indicated that mentors played a major role in advancing students nursing knowledge and this supports the findings of this study. The practice of the nurses in this nurse-led clinic evolved in relation to having a mentor to support them, and this has many implications for the organisation in view of the rapid changes in health, technology and treatment. The domain of cancer care amidst these changes also impacts on nurses working in outpatient settings. The need for flexible forms of nursing and to continually up-skill and multitask has challenged traditional nursing boundaries (Flanagan, 1998). Many patients now receive their chemotherapy treatment in the outpatient setting by nurses. Current literature reinforces the issue of ongoing professional development because nurses in rural areas are now taking on many cancer-related roles and thus need the education, knowledge and skills to fulfil their portfolios (Curtiss, 1993; Dewar et al., 2003; Wyatt, 2007; Yates et al., 2000, 2003). Patients have also become more proactive participants of their care. Their demands to know about their illness at different stages of the disease and treatment, and for information to improve their self care abilities are high (Clavarino, Lowe, Carmont \& Balanda, 2002; McCaughan \& Thompson, 2000). The role of the nurse in this cancer care setting then becomes crucial if these needs of these patient are going to be met (Clavarino et al., Sanson-Fisher et al., 2000).

For the nurses in this study maintaining their practice skills and knowledge is a balance between increasing patient and service demands against practice obligations and their own educational needs. Key concerns were the time taken off to attend courses; this is problematic organisationally as there is no one to replace the nurse if she goes away. Low patient numbers for practice development are once again commonalities shared with other studies into rural nursing issues (Dewar et al., 2003; Hegney, McCarthy, 
Rogers-Clark \& Gorman, 2002). There are the additional challenges of meeting the educational needs of the generalist nurses in this clinic who are also required to address other competencies relevant to their areas of practice. Yates et al. (2003) acknowledge the difficulties rural providers face trying to bridge knowledge gaps in professionals working in non-specialist settings. Ongoing professional development will remain a reality of the current healthcare environment (NCNZ, 2003). The nurse, by virtue of her position plays, an important role in meeting these requirements. Today's practice environment requires a process of ongoing competence review, up-to-date practice and continual refining and acquisition of skills to enable good safe outcomes (Dewar et al., 2003; Hegney et al., 2002; MacDuff \& West, 2001; Mooney, 2001). Many innovative models have been suggested to address the educational needs of rural nurses. However, the overarching theme in the literature is that educational requirements need to be tailored to the practice environment (Dewar et al., Gibb, Anderson \& Forsyth, 2004; Hegney et al., MacDuff \& West; Wyatt, 2007).

The nurses themselves in this study have suggested strategies to address their educational needs (see Chapter 6) and these should be used to inform the debate between themselves and the organisation. One way of addressing cancer care competencies in this particular situation is to perhaps adopt a model such as the one suggested by Curtiss (1993). In this model each nurse, after an educational specific needs analysis, designed their own oncology learning programme and then worked with nurse educators on and offsite to see how these could be met. This allowed fundamental knowledge gaps to be addressed before moving onto broader educational requirements. The impact of the internet and distance learning has had a major effect on the current learning environment with access to education quite literally at the fingertips of the nurse (Dykman \& Davis, 2008) and this has been important for nurses in rural areas. Currently in New Zealand there exists no clinical pathway for oncology nurses working in rural areas, therefore each nurse must seek to develop her own pathway There is also a need to look into supporting the specialist nurses up to a level cognizant with Nurse Practitioner status given service gaps, the immense responsibilities and advanced level of practice required of these nurses. 
Threats to this nurse-led service will come from the expected growth in future cancer patient numbers, and if no subsequent development and refinement of this service takes place. There will also be threats around future workforce issues given the median age of the nurses. Immediate threats come from the huge burden of responsibility some of these nurses hold and if one crucial person, for example the oncology nurse, is not available (for whatever reasons) then this service will be compromised. Threats to this service continue because of a lack of after hours support and knowledge gaps in other health professionals who have input into the service.

\section{Descriptive Theoretical Propositions}

Two descriptive theoretical propositions were developed prior to entering into this research to provide a framework and direction in determining what information should be collected and to provide links between the sources of evidence to inform the study. The study sought to test the following statements. The first proposition sought to examine how the survival and support of chemotherapy practice in rural areas was grounded in mutually beneficial relationships fostered by contextual influences in and around practice. The second statement sought to test my assumption that if attention was paid to developing a nurse's knowledge and skills, whilst providing her with access to appropriate resources these in turn would provide the patient with greater protection and improve chemotherapy treatment outcomes.

In relation to the first descriptive statement the study has shown that multiple relationships exist between this service and other providers and without these links this service would not be possible. These beneficial relationships exist because of resource constraints and geographical location and also because the healthcare service is a multidisciplinary partnership. When this case was examined in context, mutual beneficial relationships were shown to exist at many levels. They existed between the government, and the organisation and the population and are made implicit in the commitments made in the various healthcare strategies and the funding provided to improve care outcomes and for education. Relationships were also shown to exist 
between the different regions as the major city specialist service provided oncology input and nursing support and education into this area. At the organisational level multiple health providers were involved in the patient's care to ensure good outcomes, but the impact of system failures was shown in the study to significantly impact on care. Relationships were also shown to exist within the clinic between nurses and patients, and between the patients themselves. The hidden role of the clinic was shown to exist to meet a range of patient needs based on supportive relationships. Informal networks are strong and exist because the long time rural residents know each other well (Bourke et al., 2004). Relationships are stronger because of the impact of rural challenges and these are seen in the support amongst the nurses themselves to enhance practice. Bushy's (2000) work on partnership frameworks supports this viewpoint. This study has shown that beneficial relationships are the threads of support that maintain this chemotherapy service and its structural integrity. Some of these relationships are strong and others are tenuous. The study has also shown that some relationships are unequal and this is reflected in the burden of responsibility these nurses carry, however if all these threads of support are strengthened then we'll all be advancing in the same direction towards the goal of reducing healthcare inequalities.

The second proposition was that 'attention to a nurse's education and provision of appropriate resources would provide the patient with greater protection and improve chemotherapy treatment outcomes.' Without skilled nurses many rural services would not exist and patient care would be seriously compromised. The study shows that this service exists because of a nurse-led initiative to improve patient outcomes. Education is the key to implementing strategies to improve health outcomes and to professional workforce development and is recognised within the government's framework of reducing inequalities and providing population specific programmes (Health Workforce Advisory Committee, 2002). This study revealed how education was important to advancing practice so that the nurses could deliver a better, safe service. The nurses themselves spoke of how crucial to their practice was the provision of ongoing education and training. According to Beatty (2001) rural nurses require a broad knowledge base, because often their practice intersects into the domain of other health professionals 
simply because there is a shortage of skilled personnel. The nurses need education to provide effective care and for these expanding roles, and the patients need education not only about their illness but how to care for themselves. Turnbull (2001) proposes that attempts should be made to make patients safer in an active way and education is one way of addressing this issue. When taken in the context of this environment and most healthcare settings I would maintain that education of patients and nurses will provide the greatest protection and I believe this study shows this. However, although education is crucial to healthcare outcomes there are also safety indicators that are linked to resources and the attitudes, and health-seeking behaviours of patients that do put them at risk. The statement made by one of the nurses highlights this issue:

Patients believe it or not actually forget to get their bloods tested (Participant 3).

Rural nursing theory supports the role of health seeking behaviours and attitudes in determining healthcare outcomes (Bushy, 2006)

\section{Conclusion}

The rural health care network could be likened to a fabric with different woven threads, intertwined and linked. When weaknesses and holes appear in this fabric then the integrity of the structure is threatened and care is compromised. This study sought to uncover the special and unique qualities inherent in this case of chemotherapy practice. The case for practice was made implicit in the nurses' statements as they were linked to the wider literature. The study suggests that good care can be delivered in resource poor environments and that need will shape and be the impetus for service developments. This has implications for future service developments in rural areas. Despite contextual constraints people expect good quality of care whether they reside in rural or urban settings. Fostering pockets of excellence in practice requires attention to those factors that contribute to the bigger picture. In this situation this involves looking into what additional resources and support the nurses require to improve their care, the conditions under which treatment is delivered and what strategies are required to support educational development. These things require top management input into actual 
practices taking place at ground level. This study has also provided insight into how nurses perceive their practice in this clinic and provided examples of how these nurses worked to cushion their patients from situational influences. Education and supportive networks were shown to be crucial to the sustainability of this service. In concluding this discussion I would like to say that the nature of practice within a nurse-led clinic has been revealed. This thesis is also a story about working together to support skills acquisition and confidence. It's about these nurses learning from me regarding my oncology and palliative care skills and in turn it's about me learning from them about rural life, nursing and learning to work in another framework from a city model. Collectively it's about us taking the best from each other to enhance and develop our nursing life experiences. The next chapter concludes with a summation of the study and recommendations for future research. 


\section{CHAPTER EIGHT: Conclusion - Laying the Fabric to Rest}

“To rest - to remain, to continue to be" (Collins et al., 2006, p. 649).

This chapter concludes this study by providing a summary of the research and key findings ending with recommendations to improve practice and suggestions for future research. This study sought to provide a descriptive account of the nature of chemotherapy practice in a rural New Zealand setting. It also sought to uncover the issues the nurses saw as impacting on their practice and to provide new information and insights into this area. The influences in and around practice have been shown to impact on the way patients access care and the way the nurses seek to meet their patient's needs. This service was borne out of a need to address the cancer burden of care experienced by patients in this region, and it is a prime example of nurses taking the initiative to improve outcomes. Linking the final threads in this fabric concludes this research project.

I utilised case study methods in this research as a strategy to uncover the unique aspects of chemotherapy practice in this rural setting. This form of qualitative inquiry allowed me to study this contemporary issue within its context and to provide a platform for the nurses' voices to be heard. Not much is known about rural chemotherapy practice in New Zealand and this study contributes to the body of nursing knowledge that hopefully will inform the debate to advocate for improved services. The propositions developed prior to conducting the research, provided a roadmap to direct my attention as the researcher to what should be examined in the study. In line with these hypothetical statements, relationships were shown to be crucial to the survival and sustainability of chemotherapy in rural settings and cancer care outcomes. Some of these relationships appeared to be strong, others tenuous, whilst some appeared unequal particularly when it came to the burden of responsibility held by these nurses. Significant barriers to access specific practice education were identified in this study. Education was also shown to be an important factor to support and advance practice and to improve the quality of patient care in this setting. The support of mentored relationships is an important aspect of the 
study to emerge as it played a crucial role in advancing the practice of these nurses. The nurses themselves had developed some strategies to overcome gaps in their knowledge and have in turn identified ways in which the organisation can support them in their ongoing professional development. Some of the strategies mentioned have the potential to assist other rural health providers striving to meet the educational needs of their nurses albeit within a climate of fiscal and resource constraints.

This case is also important in view of the changing landscape of New Zealand's healthcare environment and the future shape and direction of nurse-led services. Cancer has emerged as the leading cause of death and nurses will play a key role in delivering treatments and developing services that are appropriate to the context in which care is delivered. This also has implications for rural areas who continue to experience issues around the recruitment and retention of skilled healthcare professionals. The insights of experienced nurses as novice practitioners in a speciality practice were highlighted. The study findings challenge assumptions that to provide a speciality service the nurse needs to be operating from a specialised body of nursing knowledge. The knowledge of these nurses is developing and is shaped and informed by the context of their practice and their experiences are borne out of a need to provide a service where previously none existed.

Barriers to practice were shown in this study to be opportunities to enhance care and these nurses were innovative in the way they practiced, to cushion their patients from the impact of situational influences. Humour in practice, multiple skills and scheduling appointments to meet a range of patient needs suggest cushioning strategies to improve outcomes. The patient in today's healthcare environment will require the input of several members of the multidisciplinary health team as the different systems intersect to deliver care. The impact of system failures in one area of a healthcare system was shown in this study to influence outcomes in the clinic. Quality improvement outcomes have become increasingly linked to aligning the different components of a system to provide a seamless interface for the patient. It is hoped that the findings of this study will be 
utilised to foster and improve service networks so that good consistent care is maintained and not put under threat.

Changes within the cancer care setting will continue and rural New Zealand areas will not be exempt from these influences. This study provides a first time account of practice, locating a specialised service delivering chemotherapy in a rural New Zealand area. It is my hope that this case study will be useful to other rural health providers facing similar issues and that the knowledge gleaned will in turn contribute to ongoing debate and overall service refinement. The findings of this research should be viewed cautiously and within context of this particular practice setting. The metaphorical fabric that is this case study has revealed the multiple threads of influence that maintain its structure. These intrinsic and extrinsic threads allow us a glimpse into the complex nature of service delivery that appears to be characteristic of our healthcare service and peculiar to rural services. This study also provides a set of recommendations which are given in the spirit of uplifting practice in this nurse-led service.

\section{Recommendations to improve practice}

Ongoing commitment and improvement of healthcare services is a remit of all healthcare providers and this service like any other needs to be evaluated periodically to identify service gaps and ascertain if it is meeting the needs of the population it serves. An urgent need assessment of the service is needed to identify what additional resources and support these nurses require to maintain safe practice. Included in this assessment should be an evaluation of actual practices in the clinic. It should also encompass the role of the oncology and palliative care nurse specialists to ascertain the range and extent of their responsibilities. This is to identify how their practice could be supported with a view to sharing the burden of responsibilities these nurses carry. Attention should also be paid to workforce issues so that replacements are provided to allow time off to study and for sick and annual leave. Attention should also be paid to developing an improved after hours support for chemotherapy and oncology patients. This may mean looking at instituting a local after hour's telephone support system particularly for those patients identified to have complex needs. Telemedicine may well be the answer to improving 
the consultative process particularly when patients will not be seen for a prolonged period of time between treatments. However, as a priority management efforts are needed to strengthen existing structures and systems because failures in other departments have been proven to significantly impact on care in the clinic. An education specific needs analysis of each nurse should be undertaken to identify specific skills and knowledge that they need to improve their individual practice in the clinic. Once this is identified, nurses could then work with the onsite clinical nurse educators and the offsite oncology nurse educator to adopt strategies and identify resources that can be utilised to meet these needs. Temporary clinical placements to develop expertise and secondment of skilled nurses for training and practice development are just some methods that can be employed. Competency issues in nurses and any other health professionals coming into contact with patients receiving chemotherapy need to be addressed. Attention to these knowledge gaps particularly on the wards will enable improved care of those with post chemotherapy complications. Support and development of an oncology and palliative care nurse practitioner role with limited prescribing rights. Expand the role of the clinic to include regular wellness and symptom management consultations for cancer patients who are not receiving chemotherapy. This will entail an approach that is proactive instead of reactive and may well reduce the pressures on the oncology clinics and in turn meet a range of unmet (psychological) needs of these patients.

\section{Future Research}

There is a need for research into chemotherapy practices in other rural New Zealand settings. It would be useful to know the extent and nature of these practices, uncovering issues affecting care and in turn contributing to a knowledge base which can be used to improve and develop rural services. It would also be useful to research these services from the perspective of the patients, and from those who provide support for these services. Their view point into practice issues and care is a valuable way of identifying care gaps within the service with the aim of improved health care outcomes. Additionally there is a need for research into the role of the rural oncology and palliative care specialist nurses in order to ascertain the range and extent of their responsibilities and to assist with clear well defined clinical pathways to aid professional development. 


\section{Celebration of resilience}

I end this thesis with a section celebrating the resilience of these rural nurses. I left the area at the end of my tenure with a feeling of profound respect and admiration for the work these people do. For a brief period of time I was one of them (a rural nurse). I kept a journal during my time in their place and I now refer to this record to provide insight into the nature and spirit of this place. After a particularly busy day at the clinic I wrote this in my journal.

One of the strengths of this clinic is its ability to be flexible to accommodate the patient's needs. Often chemotherapy is given on non scheduled days to accommodate patients who live long distances away so that they can see the oncologist on the same day they receive treatment. This saves the patient an additional trip or even the cost of an overnight stay in town. As nurses, we keenly feel the stresses and strains of the day however; we offer each other support and guidance when dealing with the issues that crop up. The patients in the clinic are unaware of our feelings and the usual clinic atmosphere of a relaxed jovial environment prevails. Chemotherapy treatments are stressful, more so when affected by service issues, however, our patients don't need to see us stressed or know about our difficulties. We are professional at all times; we can't let our patients see the impact wider issues have on us. We continue with rigid safety checks when alone and when together, because the fact that we are working in isolation is ever present in our minds. We are profoundly aware that our unsafe actions could have dire consequences for our patients. Despite these issues the chemotherapy clinic continues to project an atmosphere of friendliness, warmth, support and professionalism. Patients are grateful to be receiving treatment in their local area and are somewhat accepting of delays and setbacks which may not be the case in other centres. My role and that of the other nurses is immense. Wider issues have impacted on care today. It's not simply a matter of handing over your tasks to someone else to dobecause you're it, the only one.

Most of the nurses in this study are long time rural residents and when they say they know their patients well, they truly mean this. They are active community members and 
often met their patients in other social domains. I found a spirit of friendliness and support to exist in this service and the staff were prepared to go to great lengths to help each other and their patients. The multiple roles they each hold is testament to the fact that they care enough about patient care to meet their patient's needs at many levels. Despite the many barriers to ongoing professional development these nurse are keen to learn, and it's not something they have to do, but something they want to do. Without the dedication and commitment of rural nurses, many healthcare services would not exist. This thesis celebrates these nurses' contribution to this community, in providing a specialised service to cancer patients in this region. 
APPENDIX A: LIST OF ISSUE STATEMENTS \& QUESTIONS

According to Stake (1995) these can be stated in anyway that is helpful, they can appear as cause and effect relationships.

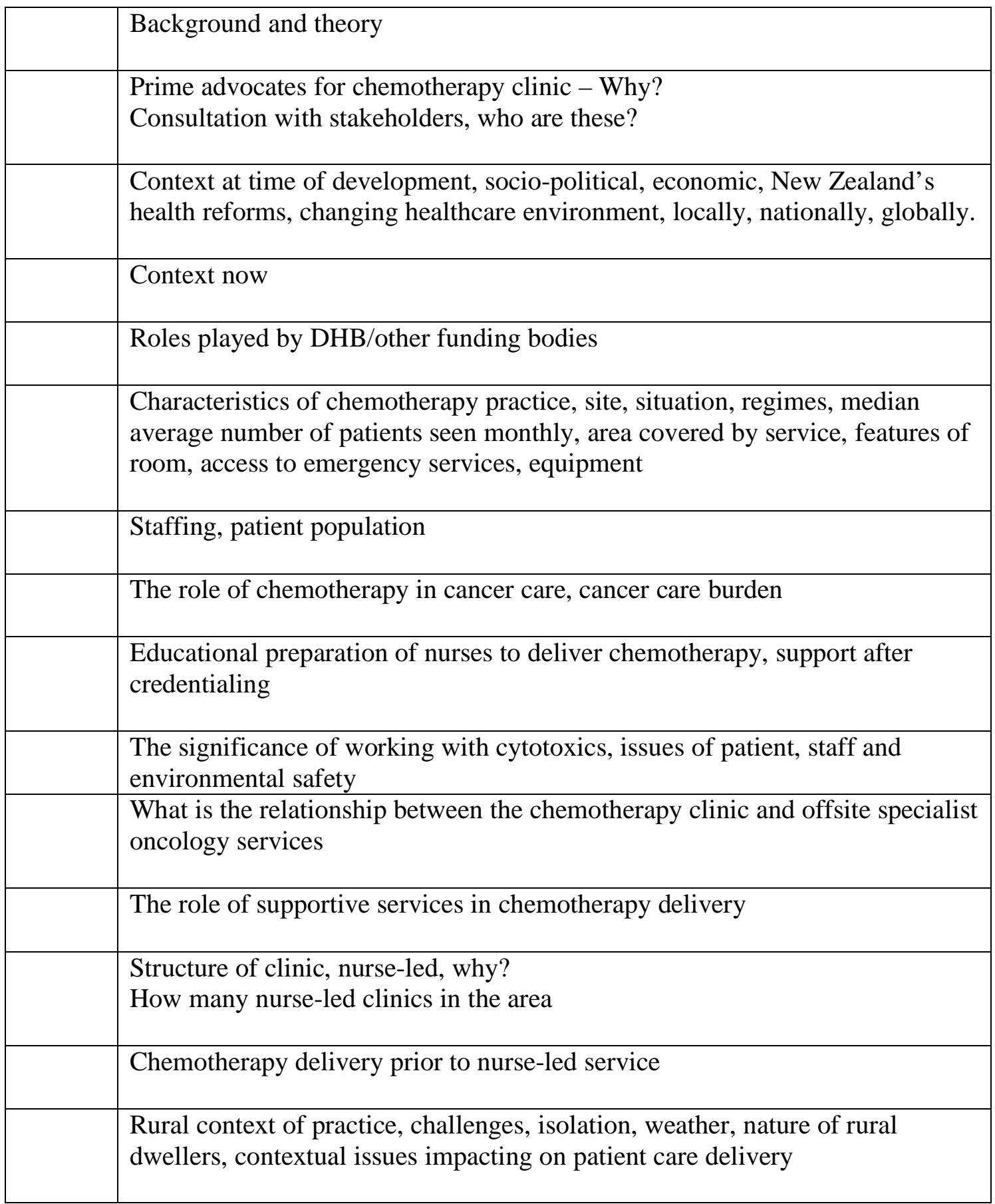




\section{APPENDIX B: PROSPECTIVE PARTICIPANTS INFORMATION FORM}

\section{A descriptive case study of practice development in a rural nurse-led chemotherapy clinic}

Thankyou for taking the time to consider my research proposal. As part of my studies towards a completion of a Clinical Master's in palliative care at Victoria University, I am undertaking qualitative research into rural chemotherapy practice and the issues that impact on safe care.

\section{Research Question}

What is the nature of practice in a rural nurse-led chemotherapy clinic?

The aims of this study are to:

- Specifically document and observe the practice of chemotherapy nurses working in a rural New Zealand setting

- Identify the issues that nurses identify as affecting their practice

- Provide a case study of cancer nursing practice and recommendations for service improvements that lead to improved patient outcomes

\section{Selection Criteria}

To be eligible for participation in this study, key informants need to be:

- Nurses working in the nurse-led chemotherapy clinic

\section{Participant Involvement}

Should you agree to take part in this research you will be asked to participate in a face to face semi-structured interview with the researcher and permission will be sought from you to observe your nursing practice during a clinic. The interview will take approximately 45 to 60 minutes and may be tape recorded. A time and place that is convenient and mutually agreeable to both participant and researcher will be selected. After the interview you will receive a transcript of the proceedings to verify that this is a true record of your interview and to allow for any changes you may wish to make. The 
analysis of your interview may result in additional questions which may be the focus of a brief 30 minute interview, or a telephone or email conversation. Observation of your nursing practice will involve the researcher watching the way you work, documenting the activities and processes of the clinic in an unobtrusive manner. You will be informed when your practice is being observed for research purposes. At the end of the chemotherapy clinic the researcher will sit down with you to discuss her observations to ascertain if her accounts of events are a true reflection of what has happened and you will be given an opportunity to comment on these observations. Since your nursing practice involves patient care, a few days prior to attending the chemotherapy clinic prospective patients will be informed about the study through a telephone conversation and permission sought to observe practice. If patient interest is expressed in the study a copy of the information sheet will be sent to them. If the patient expresses concern about being observed then the researcher will not observe that particular chemotherapy session as part of the study. At the conclusion of this research you will receive a summary of the findings. The results will inform the thesis and may be presented at local or international conferences.

\section{Confidentiality and anonymity}

Anonymity, confidentiality and privacy of participants will be ensured by the use of pseudonyms, numerical codes and illustrative narratives with personal identifiers removed. Names of places and location will not be referred to in this study. Pre- research confidentiality agreements between participants and researcher and between researcher and transcriber will be signed. Only the researcher and research supervisor will have access to all of the transcripts.

\section{Data collection and storage}

Access to data material will be limited to the researcher and supervisor and material will be kept in a locked filing cabinet. At the completion of the study research notes and tapes will continue to be kept in secure storage and will be retained for potential development of a pilot into a more comprehensive study dealing with rural chemotherapy practices. Any identifying personal information will be destroyed. 


\section{Withdrawal from the research}

You have the right to decline to participate in this study without any disadvantage to you either in the form of censure, coercion or penalty. If you would like to be a participant you may withdraw from the study at any time if you so wish. You also have the right to refuse any question asked of you and to say what information can or cannot be used in the study. You also have the right to ask that the recorder be turned off at any stage during the interview. It is possible, but rare that you may experience some personal distress during the revelation of information during the interview. If this is an issue for you, counselling and debriefing sessions are available.

The contacts for counselling are:

Picc Neilson

Phone 037680499 extension 2710

Or

Employee Assistance Programme Counsellors

Ursular Niclaus, phone 03 7686828: Claire Holley, phone 037689917

If you have any queries or concerns regarding your rights as a participant in this study you may wish to contact a Health and Disability Advocate, telephone

South Island except Christchurch 08003777766

Christchurch

033777501

\section{Consent}

Participation in this research project is entirely voluntary and if you agree to be a participant, please complete the enclosed consent form and return this in the self addressed envelope to Glynnis James. Once I have received your consent form I will contact you and arrange a suitable date and time for an interview.

This study has received ethical approval from the Upper South A Ethics Committee 
If you have questions concerning the study either now or in the future you can contact the following people:

Glynnis James, Researcher

Phone 033479307

Or:

Dr Margaret Martin, (Research Supervisor)

Victoria University of Wellington

Phone 044636140

Email: margaret.martin@vuw.ac.nz

Thank you for considering participation in this research project.

Regards

Glynnis James

Researcher 


\section{APPENDIX C: INFORMED CONSENT FORM}

\section{Research Title: What is the nature of practice in a rural nurse-led chemotherapy clinic?}

Researcher: Glynnis James

I have read the information sheet concerning this research project and understand what it entails.

I give my consent to be interviewed by the researcher about information pertaining to the study and rural chemotherapy practice. I understand that the interview is part of this process and may lead to greater understanding of the subject.

I agree to be interviewed at a date and time that is mutually agreeable to both myself and the researcher and in a place where privacy can be assured. I understand that the interview may take up to 45 minutes and may be taped.

I agree to have my nursing practice observed during the chemotherapy clinic. I understand that the researcher will be observing my work and not the patients.

I understand that I was selected to participate in this study because of the knowledge that I hold which may inform the research.

The consent I give is voluntary and I realise that I can withdraw from the study at any time without censure or risk and that my participation will not influence my relationship with the researcher or my work organisation.

I am aware that the information I share with the researcher will be reviewed and accessed by the research supervisor only and that my identity and anonymity will be preserved.

I appreciate that the study has ethical approval and that I can contact Glynnis James or the research supervisor Margaret Martin if any concerns arise.

I consent to the information gathered about me being used for future research into rural chemotherapy studies subject to ethical approval being given by a New Zealand accredited ethics committee.

YES/NO

I agree to take part in this study under the above conditions and those set out in the information sheet.

Date: Research Participants Signature.

Date: Researchers Signature. 


\section{APPENDIX D. CONFIDENTIALITY STATEMENT}

(This will be signed prior to any participant observation or interviews)

Thank you for agreeing to take part in this research project entitled, 'The nature of rural nurse-led chemotherapy practice.' This project is being undertaken by Glynnis James, a student of Victoria University of Wellington as part of tertiary studies towards completion of master's degree in palliative care. The research project is being supervised by Dr Margaret Martin, School of Nursing and Midwifery, Victoria University of Wellington.

I would like to emphasise that:

- your participation is entirely voluntary

- you are free to refuse to answer any questions

- you are free to withdraw from the research project at any time

- You will always be informed if your practice is being observed for research purposes

I would like to assure you that all data collected in this interview and during observation will be treated as confidential and will only be available to the above mentioned people. Excerpts from the interview or observation of practice may be used in the final research report but will be done so anonymously or changed in such a way that any identifying features are removed. Any changes to these conditions will be made only with the approval and consent of the participant.

This study has received ethical approval from the Upper South A Ethics Committee

Please sign the form to show that you have read the contents.

Signed:

Printed Name: 


\section{APPENDIX E. LIST OF INTERVIEW QUESTIONS}

1. How many years have you being nursing?

2. How long have you being involved in the chemotherapy clinic?

3. What influenced your decision to work in this area?

4. Besides working in the chemotherapy clinic what other roles are you currently involved within the hospital?

5. What do you perceive to be your role in this clinic?

6. Has your role changed in anyway over the last six months?

7. What do you see are the issues relating to safety and risk regarding the following?

- The patient

- Yourself

- Disease

- Environment

8. Can you describe a situation in which you felt unsafe whilst working in the clinic?

9. What do you feel are the strengths of the clinic?

10. How can the clinic be improved to enable it to function more effectively?

11. What is your vision for this service? 


\section{REFERENCES}

Ammenwerth, E., Iller, C., \& Mansmann, U. (2003). Can evaluation studies benefit from triangulation? International Journal of Medical Informatics, 70, 237-248.

Arbon, P. (2004). Understanding experience in nursing. Journal of Clinical Nursing, 13, $150-157$.

Ashton, T. (1999). The health reforms: To market and back. In J. Boston, P. Dalziel \& S. St John (Eds.), Redesigning the welfare state in New Zealand: Problems, policies, prospects (pp. 134-153). Auckland: Oxford University Press.

Barnett, J. R. (2000). Geographic perspectives on hospital restructuring and its impact in New Zealand. New Zealand Medical Journal, 113, 125-128.

Barnett, J. R., \& Coyle, P. (1998). Social inequality and general practitioner utilisation: Assessing the effects of financial barriers on the use of care by low income groups. New Zealand Medical Journal, 66-70.

Beatty, R. M. (2001). Continuing professional education, organisational support, and professional competence: Dilemma of rural nurses. The Journal of Continuing Education in Nursing, 32(5), 203-209.

Benner, P. (1984). From novice to expert. Menlo-Park, California: Addison-Wesley

Bergen, A., \& While, A. (2000). A case for case studies: Exploring the use of case study design in community nursing research. Journal of Advanced Nursing, 31(4), 926934.

Block, L. M., Claffey, C., Korrow, M. K., \& McCaffrey, R. (2005). The value of mentorship within nursing organisations. Nursing Forum, 40(4), 134-128. 
Bourke, L., Sheridan, C., Russell, U., Jones, G., De-Witt, D., \& Liaw, S. (2004). Developing a conceptual understanding of rural health practice. Australian Journal of Rural Health, 12, 181-186.

Buchsel, P., \& Glennon, C. (2005). Ambulatory care administrative concepts: An overview. In P. C. Buchsel \& C. H. Yarbro (Eds.), Oncology nursing in the ambulatory setting: Issues and models of care (2nd ed., pp. 1-31). Sudbury, MA: Jones and Bartlett.

Bushy, A. (2000). Orientation to nursing in the rural community. Thousand Oaks, CA: Sage Publications.

Bushy, A. (2006). Rural nursing practice and issues. Retrieved 21 March, 2006, from, http://www.nursingworld.org/mods/mod700/rurlfull.htm

Clavarino, A. M., Lowe, J. B., Carmont, S., \& Balanda, K. (2002). The needs of cancer patients and their families from rural and remote areas of Queensland. Australian Journal of Rural Health, 10, 188-195.

Collins, C., Cross, R., Gilmour, L., Holmes, A., Mackie, W., \& Weber, P. (Eds.). (2006) Collins english dictionary \& thesaurus (3rd ed.). Glasgow: HarperCollins.

Corner, J. (2003). The role of nurse-led care in cancer management. The Lancet, 4, 631636.

Cox, K., \& Wilson, E. (2003). Follow-up for people with cancer: Nurse-led services and telephone interventions. Journal of Advanced Nursing, 43(1), 51-61.

Curtiss, C. P. (1993). Trends and issues for cancer care in rural communities. Nursing Clinics of North America, 28(1), 241-251.

Day, G. E., Minichiello, V., \& Madison, J. (2006). Nursing morale: What does the literature reveal? Australian Health Review, 30(4), 516-524. 
Dewar, A., Steginga, S. K., Dunn, J., \& McCarthy, A. (2003). Delivering cancer nursing education to regional rural and remote area nurses in Queensland. Cancer Forum, 27(2), 111-114.

Doolan-Noble, F., McKinlay, E., \& Cormack, D. (2006). The journey of treatment and care for people with cancer on the west coast. Wellington, New Zealand: West Coast District Health Board

Dykman, C. A., \& Davis, C. K. (2008). Part one: The shift toward online education. Journal of Information Systems Education, 19(1), 11-16.

Egan, M., \& Dowling, M. (2005). Patient satisfaction with a nurse-led oncology service. British Journal of Nursing, 14(21), 1112-1116.

Egglefield Beaudoin, L., \& Edgar, L. (2003). Hassles: Their importance to nurses' quality of work life. Nursing Economics, 21(3), 106-113.

Erlandson, D. A., Harris, E. L., Skipper, B., \& Allen, S. D. (1993). Doing naturalistic inquiry: A guide to methods (pp. 96-99). Thousand Oaks, CA: Sage Publications.

Evans, R. J., \& Donnelly, G. W. (2006). A model to describe the relationship between knowledge, skill and judgement in nursing practice. Nursing Forum, 41(4), 150157.

Fitzsimmons, D., Hawker, S. E., Simmonds, P., George, S. L., Johnson, C. D., \& Corner, J. L. (2004). Nurse-led models of chemotherapy care: Mixed economy or nursedoctor substitution? Journal of Advanced Nursing, 50(3), 244-252.

Flanagan, J. (1998). Achieving partnership: The contribution of nursing education to the production of a flexible workforce. Journal of Nursing Management, 6, 129-136.

Gauld, R. (2001). Revolving doors: New Zealand's health reforms. Wellington, New Zealand: Victoria University of Wellington. 
Gibb, H., Anderson, J., \& Forsyth, K. (2004). Developing support for remote nursing education through workplace culture that values learning. Australian Journal of Rural Health, 12, 201-205.

Gilbar, P. (1999). Cancer chemotherapy. The Australian Journal of Hospital Pharmacy, 29(2), 100-102.

Gilbar, P. (2001). Preventing medication errors in cancer chemotherapy referred to rural and remote hospitals. Australian Journal of Rural Health, 9, 47-51.

Gilchrist, A. (2006). Maintaining relationships is critical in network's success. HealthcarePapers, 7(2), 28-31.

Gillis, A., \& Jackson, W. (2002). Research for nurses: Methods and interpretation (pp. 423-470). Philadelphia: F. A. Davis Company.

Goodman, M., \& Lynch, C. (2007). Primary Health Care Nursing Team 2006-2007. Auckland: Counties Manukau District Health Board.

Graziano, A. M., \& Raulin, M. I. (1993). Research methods: A process of inquiry. New York: Harper Collins.

Grey, M. (1994). Data collection methods. In G. LoBiondo-Wood \& J. Haber (Eds.), Nursing Research: Methods, critical appraisal, and utilization (3rd ed., pp. 344364). St Louis: Mosby.

Hancock, D. R., \& Algozzine, B. (2006). Doing case study research. New York: Teachers College Press.

Health Workforce Advisory Committee. (2002). The New Zealand health workforce. Wellington, New Zealand: Ministry of Health.

Hegney, D., McCarthy, A., Rogers-Clark, C., \& Gorman, D. (2002). Retaining rural and remote area nurses. Journal of Nursing Administration, 32(3), 128-135. 
Hodgson, P. (2005). Cancer control strategy initiatives. Retrieved 13 April, 2008, from http://www.beehive.govt.nz/node/24510

Hodgson, P. (2006). Minister outlines nurses' key role in primary healthcare strategy. Kai Tiaki Nursing New Zealand, 8, 8.

Hoelz, T. M., Sladek, M. L., \& Michaelson, P. L. (2007). Blending nursing roles in oncology and imaging: An innovative strategy. Oncology Nursing Forum, 34(1), 27-31.

International Council of Nurses. (1998). Scope of nursing practice. Retrieved 14 April, 2008, from http://www.icn.ch/psscope.htm

Jacobs, S. (2003). Advanced nursing practice: Time and meaning. Nursing Praxis in New Zealand, 19(3), 29-39.

Jacobs, S. (2000). Credentialing: Setting standards for advanced nursing practice. Nursing Praxis in New Zealand, 16(2), 38-46.

Johnson, L., Zichi Cohen, M., \& Hull, M. (1994). Cultivating expertise in oncology nursing: Methods, mentors and memories. Oncology Nursing Forum, 21(8), $27-$ 34.

Joiner, T., \& Bartram, T. (2004). How empowerment and social support affect Australian nurses' work stressors. Australian Health Review, 28(1), 56-64.

Jones, L. A., Chilton, J. A., Hajek, R. A., Iammarino, N. K., \& Laufman, L. (2006). Between and within: International perspectives on cancer and health disparities. Journal of Clinical Oncology, 24(14), 2204-2208.

Kearney, N. (1999). New strategies in the management of cancer. Cancer Nursing, 22(1), 28-33.

Kilcullen, N. M. (2007). Said another way. Nursing Forum, 42(2), 95-104. 
Lamkin, L., Rosiak, J., Buerhaus, P., Mallory, G., \& Williams, M. (2001). Oncology nursing society workforce survey Part 1: Perceptions of the nursing workforce environment and adequacy of nurse staffing in outpatient and inpatient oncology settings. Oncology Nursing Forum, 28(10), 1545-1552.

Lasselter, J. H., \& Wernick, M. L. (2003). Medical errors drug-related problems and medication errors. Journal of Nursing Care Quality, 18(3), 175-181.

Liehr, P. R., \& Taft Marcus, M. (1994). Qualitative approaches to research. In G. LoBiondo-Wood \& J. Haber (Eds.), Nursing research: Methods, critical appraisal and utilization (3rd ed., pp. 253-285). St Louis: Mosby.

Lin, L., \& Liang, B. (2007). Addressing the nursing work environment to promote patient safety. Nursing Forum, 42(1), 20-30.

Lincoln, Y. S., \& Guba, E. G. (1985). Naturalistic inquiry. Thousand Oaks, CA: Sage Publications.

Loftus, L. A., \& Weston, V. (2001). The development of nurse-led clinics in cancer care. Journal of Clinical Nursing, 10, 215-220.

Long, K. A., Ellis Scharff, J., \& Weinert, C. (1997). Advanced education for the role of rural nurse generalist. Journal of Nursing Education, 36(2), 91-94.

Macduff, C., Leslie, A., \& West, B. (2001). Ambulatory chemotherapy - towards best community practice. Journal of Clinical Nursing, 15(7), 1-6.

MacLeod, M., Browne, A. J., \& Leipert, B. (1998). Issues for nurses in rural and remote Canada. Australian Journal of Rural Health, 6, 72-78.

Mays, N., \& Pope, C. (1995). Qualitative research: Rigour and qualitative research. British Medical Journal, 311, 109-112. 
McCarthy, A., \& Hegney, D. (2001). A review of the educational needs of nurses administering cancer chemotherapy in rural and remote areas of Queensland. Cancer Forum, 25(1), 17-19.

McCarthy, A., Hegney, D., Brown, L., Gilbar, P., Robert-Brodribb, T., \& Swales, J. (2003). Characteristics of chemotherapy practice in rural and remote area health facilities in Queensland. Australian Journal of Rural Health, 11, 138-144.

McCaughan, E. M., \& Thompson, K. A. (2000). Information needs of cancer patients receiving chemotherapy at a day-care unit in Northern Ireland. Journal of Clinical Nursing, 9, 851-858.

McCavana, P. (2000). Delivering chemotherapy in rural areas: Can it work? Nursing Times, 96(35), 35-36.

Meretoja, R., Eriksson, E., \& Leino-Kilpi, H. (2002). Indicators for competent nursing practice. Journal of Nursing Management, 10, 95-102.

Ministry of Health. (2000). The New Zealand Health Strategy. Wellington, New Zealand: Author.

Ministry of Health. (2001a). He Korowai Oranga: Maori health strategy discussion document. Wellington, New Zealand: Author.

Ministry of Health. (2001b). The New Zealand Palliative Care Strategy. Wellington, New Zealand: Author.

Ministry of Health. (2001c). The Primary Health Care Strategy. Wellington, New Zealand: Author.

Ministry of Health. (2002a). Clinical Training Agency strategic intentions 2003-2012. Wellington, New Zealand: Author.

Ministry of Health. (2002b). Reducing Inequalities. Wellington, New Zealand: Author. 
Ministry of Health. (2003a). The New Zealand Cancer Control Strategy. Wellington, New Zealand: Ministry of Health and the New Zealand Cancer Control Trust. Ministry of Health. (2003b). Whakatohutia te Orange Tangata: A framework for activating Primary Health Care Nursing in New Zealand. Wellington: Author.

Ministry of Health. (2005). The New Zealand cancer control strategy action plan 20052010. Wellington, New Zealand: Author.

Ministry of Health. (n. d.). Innovative models of Primary Health Care Nursing. Retrieved 16 April, 2008, from http://www.mohgovt.nz/moh.nsf/indexmh/nursing-in

Montagu, T. (2006). Patient-provider partnerships in healthcare: Enhancing knowledge translation and improving outcomes. HealthcarePapers, 7(2), 53-61.

Mooney, K. H. (2001). Advocating for quality cancer care: Making evidence-based practice a reality. Oncology Nursing Forum, 28(2), 17-21.

Moore, A. (1997). Supportive models: Nurse-led clinics. Nursing Standard, 11(43), 2627.

Moore, D., \& Sweedman, M. (2004). Advanced nursing practice in the oncology setting: A case study. The Australian Journal of Cancer Nursing, 5(2), 16-24.

New Zealand Nurses Organisation. (2004). Recommendations for the administration of cytotoxic agents by nurses. Wellington: NZNO Cancer Nurses Section.

New Zealand Public Health and Disability Act No 9, New Zealand Statues (2000).

New Zealand Tourism. ((2006)). West Coast regional information. Retrieved 25 June, 2007, from http://www.tourism.net.nz/new-zealand/regions/west-coast/region...

Nursing Council of New Zealand. (2003). Continuing competence framework. Retrieved 1 April, 2008, from, http://www.nursingcouncil.org.nz. 
Parish, C. (2000). Patients like nurse-led aftercare cancer clinics. Nursing Standard, $9(14), 6$.

Pearson, A. (2002). Clinical nurse specialists. International Journal of Nursing Practice, $8(6), 511-514$

Pegram, A. (2000). What is case study research? Nurse Researcher, 7(2), 5-16.

Primary Health Care Nurse Innovation Evaluation Team [PHCNIET]. (2007). Overview of the evaluation of the eleven primary health care nursing innovation projects: A report to the Ministry of Health by the primary health care innovation evaluation team. Wellington, New Zealand: Ministry of Health.

Raja-Jones, H. (2002). Role boundaries - research nurse or clinical nurse specialist? A literature review. Journal of Clinical Nursing, 11(4), 415-420.

Richardson, S. (2005). Incorporation of research into clinical practice: The development of a clinical nurse researcher position. Nursing Praxis in New Zealand, 21(1), 3342.

Roberts, K., \& Taylor, B. (2002). Nursing research process: An Australian perspective (2nd ed.). Melbourne, Australia: Nelson Thompson Learning.

Rosenberg, J. P., \& Canning, D. F. (2004). Palliative care by nurses in rural and remote practice. Australian Journal of Rural Health, 12, 166-171.

Ross, J. (1999). The development of the advanced role of rural nurses in New Zealand. Australian Journal of Rural Health, 7, 253-257.

Sandelowski, M. (1996). One of the liveliest number: The case orientation of qualitative research. Research in Nursing \& Health, 19, 525-529.

Sanson-Fisher, R., Girgis, A., Boynes, A., Bonevski, B., Burton, L., \& Cooke, P. (2000). The unmet supportive needs of patients with cancer. Cancer 88(1), 226-237. 
Schulmeister, L. (1999). Chemotherapy medication errors: Descriptions, severity and contributing factors. Oncology Nursing Forum, 26(6), 1033-1040.

Schulmeister, L. (2005). Ten simple strategies to prevent chemotherapy errors. Clinical Journal of Oncology Nursing, 9(2), 201-205.

Sims, D. (2004). The benefits and challenges of one New Zealand nursing undergraduate clinical education model: A case study. Unpublished Masters Degree, Victoria University Wellington.

Smith, J., \& Topping, A. (2001). Unpacking the 'value added' impact of continuing professional education: a multi-method case study approach. Nurse Education Today, 21, 341-349.

Stake, R. (1995). The art of case study research. Thousand Oaks, CA: Sage Publications.

Stake, R. (2000). Case studies. In N. K. Denzin \& Y. S. Lincoln (Eds.), Handbook of Qualitative Research (2nd ed., pp. 435-454). Thousand Oaks, CA: Sage Publications.

Statistics New Zealand. (2006). People. Retrieved 25 June, 2007, from, http://www.stats.govt.nz/urban-rural-profiles/highly-rural-remoteareas/people.htm

Tabari-Khomeiran, R., Kiger, A., Parsa-Yekta, Z., \& Ahmadi, F. (2007). Competence development among nurses: The process of constant interaction. The Journal of Continuing Education in Nursing, 38(5), 211-219.

Tanghe, A., Paridaens, R., Evers, G., Vantongelen, K., Aerts, R., Lejeune, M., et al. (1996). Case study of quality assurance in the administration of chemotherapy. Cancer Nursing, 19(6), 447-454. 
The West Coast Development Trust. (2005). Regional profile. Greymouth: Author. Turnbull, J. E. (2001). All components of the system must be aligned. HealthcarePapers, 2(1), 38-43.

Wellington School of Medicine. (2001). An assessment of health needs in the West Coast District Health Board. Wellington, New Zealand: Author.

Wikipedia. (2007). West Coast New Zealand. Retrieved 25 June 2007 from, http://en.wikipedia.org/wiki/West_Coast_New Zealand.

Wholey, D., Moscovice, I., Hietpas, T., \& Holtzman, J. (2004). The environmental context of patient safety and medical errors. The Journal of Rural Health, 20(4), 304-313

Wiles, R., Postle, K., Steiner, A., \& Walsh, B. (2001). Nurse-led intermediate care: An opportunity to develop enhanced roles for nurses? Journal of Advanced Nursing, $34(6), 813-821$.

Wilkes, L., White, K., \& O'Riordan, L. (2000). Empowerment through information: Supporting rural families of oncology patients in palliative care. Australian Journal of Rural Health, 8, 41-46.

Wyatt, D. (2007). How do participants of a post registration oncology nursing course perceive that the course influences their practice? - A descriptive survey. European Journal of Oncology Nursing, 11, 168-178.

Yates, P. (2001). Recent developments in cancer nursing. Cancer Forum, 25(1), 3-6.

Yates, P., Dewar, A., Brown, L., Gorannson, E., Reid, A., Hargraves, M., et al. (2003). Educational preparation for chemotherapy administration: A survey of Queensland nurses. Australian Journal of Cancer Nursing, 4(2), 4-10. 
Yates, P., Hargraves, M., Prest, G., Cairns, J., Harris, K., Baker, D., et al. (2000).

Factors impacting on contemporary chemotherapy practice. Australian Journal of Cancer Nursing, 3, 2-11.

Yin, R. K. (1984). Case study research: Design and methods. Thousand Oaks, CA: Sage Publications.

Yin, R. K. (2003). Case study research: Design and methods (3rd ed.). Thousand Oaks, CA: Sage Publications.

Zucker, D. (2001). Using case study methodology in nursing research. The Qualitative Report, 6(2), 1-8. 